\title{
Numerical Taxonomy and Laboratory Identification of Actinomyces and Arachnia and some Related Bacteria
}

\author{
By K. HOLMBERG AND C.-E. NORD \\ Department of Bacteriology, National Bacteriological Laboratory, \\ S-I05 21 Stockholm, Sweden
}

(Received 17 December 1974; revised 3 April 1975)

\begin{abstract}
SUMMARY
A numerical taxonomic study was made on 49 facultative anaerobic Grampositive filamentous and/or diphtheroidal organisms isolated from dental plaques, carious dentin and faeces, together with 63 reference strains belonging to the genera Actinomyces, Arachnia, Bifidobacterium, Actinobacterium, Propionibacterium, Eubacterium and Lactobacillus. They were examined for 90 unit characters covering a wide range of tests and properties. The data were subjected to computer analysis in which the simple matching coefficient $\left(S_{\mathrm{SM}}\right)$ and the similarity index $\left(S_{J}\right)$ were calculated, and the results of single linkage techniques and an unweighted average linkage cluster analysis technique were compared.

The strains fell into six major groups (phena). The Actinomyces strains were recovered in two phena; the first contained Actinomyces israelii and the other facultative anaerobic Actinomyces, including subclusters equal to taxospecies of $A$. odontolyticus and $A$. viscosus $\mid A$. naeslundii, while the other phenon corresponded to the genera Arachnia, Actinobacterium, Bifidobacterium and Propionibacterium. The groups of Arachnia and Actinobacterium each contained one species, representing taxospecies of Arachnia propionica and Actinobacterium meyerii. Taxonomic criteria, both constant and discriminative, were selected to form a diagnostic table useful for laboratory identification of this group of organisms. Immunofluorescence supported the numerical data.
\end{abstract}

\section{INTRODUCTION}

The classification of Gram-positive diphtheroidal and/or filamentous organisms belonging to the family Actinomycetaceae and related genera is beset with many difficulties. The lines of demarcation between the actinomycete genera, and between them and related genera such as Propionibacterium and Actinobacterium, are not clear. Current taxonomic ideas concerning the family Actinomycetaceae and related organisms, and the physiology and structure of these organisms in relation to their classification and phylogenetic relationships were recently reviewed by Pine (I970) and by Cross \& Goodfellow (I973).

Few analyses have used numerical taxonomy for the classification of actinomycetes (Sneath, 1970). Melville (1965), in a numerical taxonomic study on oral actinomycetes, separated Actinomyces naeslundii, Bacterionema matruchotii and Nocardia salivae (Rothia dentocariosa) but did not recover well-defined groups of $A$. israelii, A. odontolyticus and $A$. bovis. Holmberg \& Hallander (1973) recognized well-defined groups of Rothia, Bacterionema, Nocardia and Corynebacterium equivalent to generic taxonomic status. A heterogeneous generic cluster of Actinomyces strains included a distinct taxospecies of $A$. naeslundii, $A$. viscosus, and a less well-defined group of $A$. israelii and Ar. propionica.

Lack of reliable differentiating tests based on good classifications has impeded the identification of the actinomycetes. Workers in clinical microbiology laboratories have been 
forced to depend on morphological criteria that tend to be highly variable. The ability to identify two anaerobic actinomycetes, $A$. israelii (Wolff \& Israel, I89I) and Ar. propionica (Pine \& Georg, I969), that overtly produce disease in man (Georg, I970; Brock et al. 1973) is important when evaluating their distribution and potential roles in healthy and diseased body sites. These organisms are morphologically similar to other actinomycetes of unproven pathogenicity in man (Georg, I970; Bowden \& Hardie, 1973). During the past I5 years several investigators have described a number of physiological tests for differentiating the clinically important species of Actinomyces and related bacteria (Georg, Roberstad \& Brinkman, I964; Gerencser \& Slack, 1969; Slack, Landfried \& Gerencser, I969; Georg, I970). More recently, direct immunofluorescence (Lambert, Brown \& Georg, I967; Blank \& Georg, 1968; Brock \& Georg, 1969b; Slack et al. 1969; Holmberg \& Forsum, 1973), gas chromatographic analysis of metabolic end-products in glucose fermentation ( $\mathrm{Li} \&$ Georg, I968) and paper chromatography of whole cell hydrolysates (Boone \& Pine, I968) have been introduced as an aid to identification. These new tests must now be included and evaluated in numerical taxonomic studies.

The present study was concerned with an assessment of the relationships, the construction of natural groups, and the differentiation and identification of Actinomyces and Arachnia species from related bacteria by using the method of numerical taxonomy (Methods for Numerical Taxonomy, 1970; Sneath, 1972; Sneath \& Sokal, 1973). The study combines a numerical analysis of the overall phenetic resemblance of fresh isolates and reference strains with an immunofluorescence analysis.

\section{METHODS}

Organisms. A total of 42 fresh isolates of facultative anaerobic Gram-positive nonsporeforming filamentous and/or diphtheroidal bacteria were selected from dental plaques (Holmberg, 1975) and faeces. Ten organisms typed as Actinomyces strains, seven isolates of anaerobic Gram-positive, non-sporeforming rods isolated from dentin caries and a number of reference strains were included in the study (Table I). The type strain of Clostridium perfringens, ATCCI3I24, was included to orientate it in relation to sporeforming anaerobic Gram-positive rods. The names of strains from culture collections were used according to their designations. To afford a check on the test reproducibility, one Actinomyces naeslundii strain (designated ATCCI2IO4 and NCTCI030I), one A. odontolyticus strain (designated ATCCI7982 and NCTC993I), and one Actinomyces israelii strain (designated Holm I452/45-56 and VPI3258), were replicated. All bacteria were maintained in $\mathrm{CO}_{2}$-gassed tubes containing pre-reduced anaerobically sterilized (PRAS) peptone-yeast extract (PY) broth (Anaerobe Laboratory Manual, I973), consisting of: Bacto-peptone (Difco), Io g; yeast extract (Difco), Io g; resazurin solution, $0.4 \mathrm{ml}$; salt solution, $40 \mathrm{ml}$; purified agar, $\mathrm{I} \cdot 6 \mathrm{~g}$; distilled water, I 1; cysteine- $\mathrm{HCl} . \mathrm{H}_{2} \mathrm{O}, 0.05 \mathrm{~g}$; $\mathrm{pH} 7 \cdot 0 \pm 0.2$. They were also stored lyophilized. The cultures were checked for purity at intervals throughout the study.

Methods of testing. The organisms were grown in PRAS PY broth for 5 days. The cultures were centrifuged and the organisms washed and suspended in pre-reduced salt solution, $\mathrm{pH}_{7 \cdot 2}$ (Anaerobe Laboratory Manual, 1973), to give an extinction of approximately 0.2 at $540 \mathrm{~nm}$, on a Coleman Junior spectrophotometer (Coleman Instrument Inc., Illinois, U.S.A.). The environmental anaerobic conditions were maintained during these procedures by the use of the Virginia Polytechnical Institute (VPI) anaerobic culture system (Bellco Glass Co., Vineland, New York, U.S.A.) (Moore, 1966). The bacterial suspension was then drawn into a $\mathrm{CO}_{2}$-gassed injection syringe, and approximately $0.2 \mathrm{ml}$ of the suspension inoculated into PRAS test media in $\mathrm{CO}_{2}$-gassed tubes sealed with butyl rubber 
Table I. List of organisms

\section{Organisms}

Actinomyces viscosus

A. viscosus

A. naeslundii

A. naeslundii

A. odontolyticus

A. odontolyticus

A. odontolyticus

A. odontolyticus

A. israelii

A. israelii

A. israelii

A. israelii

A. israelii

A. israelii

A. israelii

A. bovis

Arachnia propionica

Ar. propionica

Ar. propionica

Actinobacterium meyerii

Act. meyerii

Act. meyerii

Act. meyerii

Act. meyerii

Act. abscessum

Bifidobacterium breve

B. liberorum

B. adolescentis var. a

$B$. adolescentis var. b

$B$. adolescentis var. c

$B$. adolescentis var. $\mathrm{d}$

B. longum

B. eriksonii

B. bifidum

$B$. infantis

B. parvulorum

B. dentium

Propionibacterium acnes
Source*/no.

ATCCI 5987

ATCC 19246

ATCCI 2 I 04

NCTCIO3OI

ATCCI 7982

WVU 482

NCTC993 I

NCTC9935

ATCCI 2103

NCTC8047

WVU307

VPI3258

PHLS A9

PHLS AI 8

PHLS A26

ATCCI 3863

ATCC I 4 I 57

WVU346

PHLS A28

VPIOOO3

VPI86I I

VPI86I 7

VPI8620B

VPI8622

Pasteur 4567

ATCCI 5700

ATCCI 5702

ATCCI 5703

ATCCI 5704

ATCCI 5705

ATCCI 5706

ATCCI 5707

ATCCI 5423

ATCCI 5696

ATCCI 5697

ATCCI 5698

ATCC27534

ATCCI 1828
Organisms

$P$. acnes

$P$. acnes

$P$. acnes

$P$. avidum

$P$. avidum

$P$. granulosum

Lactobacillus brevis

L. fermentum

L. casei var. rhamnosus

L. catenaforme

Eubacterium limosum

E. lentum

$E$. ventriosum

Clostridium perfringens

Propionibacterium strain received as

Corynebacterium acnes group 2

Actinomyces isolates

Anaerobic 'diphtheroid' isolates from dentin caries

26 own anaerobic

'diphtheroides' from

dental plaques

16 own anaerobic

'diphtheroides' from

faeces
Source*/no.

NCTC737

CDC554

CDC605

ATCC25577

CDC9064

ATCC25564

ATCCI 4869

ATCCI493 I

AJCC7469

ATCC25536

ATCC 8456

ATCC25559

ATCC27560

ATCCI 3124

D34 (Voss)

I04/45-46 (Holm)

169/45-46 (Holm)

I 75/45-46 (Holm)

106 I/40-4I (Holm)

I452/40-4I (Holm)

I 654/40-4I (Holm)

1919/40-4I (Holm)

2129/40-4I (Holm)

A555/74 (Bodenhoff)

A752/74 (Bodenhoff)

ве8, вег 5, вег 8, ве25, ве26, ве3I, ве47,

56 to 81

82 to 97

* ATCC, American Type Culture Collection, Rockville, Maryland, U.S.A.; NCTC, National Collection of Type Cultures, Colindale, London; CDC, Center for Disease Control, Atlanta, Georgia, U.S.A.; wvU, West Virginia University, Medical School, Morgantown, West Virginia, U.S.A.; PHLS, Public Health Laboratory Service, London; VPI, Virginia Polytechnic Institute and State University, Blacksburg, Virginia, U.S.A.; Voss, Dr J. G. Voss, The Procter \& Gamble Co., Miami Valley Laboratories, Cincinnati, Ohio, U.S.A.; Pasteur, Institut Pasteur, Paris, France; Holm, Dr P. Holm, State Serum Institute, Copenhagen, Denmark; Bodenhoff, Dr J. Bodenhoff, State Serum Institute, Copenhagen, Denmark; Be, Dr G. Bowden, London Hospital Medical College, London.

membranes and screw caps (Attebery \& Finegold, 1969; Macy, Snellen \& Hungate, 1972), and on to one aerated peptone-yeast extract-glucose (PYG; Anaerobe Laboratory Manual, 1973) agar plate.

Colony morphology was examined on PRAS PYG agar slants under $\times 10$ stereomagnification. Size, shape and appearance of bacteria was determinated by dark-field microscopy by using wet preparations from the PRAS PYG agar slants. Gram reaction was examined on smears stained by Hucker's modification (Cowan \& Steel, I970). Anaerobic growth at $45^{\circ} \mathrm{C}$ in PRAS PYG broth was noted after 5 days. Spores were detected in Gram- 
stained preparations, and motility observed in drops of PYG broth on slides by dark-field microscopy. Catalase activity was tested on the anaerobic PYG agar slant, after exposure to air for at least $30 \mathrm{~min}$, by the addition of $3 \%(\mathrm{w} / \mathrm{v}) \mathrm{H}_{2} \mathrm{O}_{2}$ and observation of the evolution of gas bubbles.

Nitrate reduction, indole production, aesculin hydrolysis, liquefaction of gelatin, starch hydrolysis, $\mathrm{H}_{2} \mathrm{~S}$ production and lecithinase production were demonstrated after incubation for 5 days at $37^{\circ} \mathrm{C}$ in media and reagents devised by Holdeman and Moore (Anaerobe Laboratory Manual, I973). Reduction of nitrate to nitrite was detected in oxygen-free indole-nitrite medium (BBL) without cysteine- $\mathrm{HCl}$ and resazurin, by adding $0.5 \mathrm{ml}$ of $\mathrm{I} \cdot 0 \%(\mathrm{w} / \mathrm{v})$ sulphanilic acid in $5 \mathrm{M}$-acetic acid, followed by $0.5 \mathrm{ml}$ of $0.6 \%(\mathrm{w} / \mathrm{v})$ dimethyl$\alpha$-naphthyl-amine in $5 \mathrm{M}$-acetic acid. The development of red colour indicated a positive result. False negatives were avoided by adding approximately I $\mathrm{mg}$ zinc dust $/ \mathrm{ml}$ culture. Indole production in PY medium was detected by Kovac's reagent. The development of a pink to red colour in the reagent was recorded positive. Aesculin hydrolysis was studied in tubes containing PY broth with $0.5 \%(\mathrm{w} / \mathrm{v})$ aesculin. Hydrolysis was demonstrated by adding drops of an aqueous $\mathrm{I} \cdot 5 \%(\mathrm{w} / \mathrm{v})$ ferric citrate solution. Liquefaction of gelatin, demonstrated by the failure to solidify in the refrigerator after incubation as compared with controls of uninoculated tubes of gelatin, was recorded as positive. Hydrolysis of starch was tested by means of PY starch medium and Lugol's iodine solution. The test for $\mathrm{H}_{2} \mathrm{~S}$ production was made in a medium devised by Holdeman and Moore (Anaerobe Laboratory Manual, 1973). Development of black colour in the medium after incubation was recorded as $\mathrm{H}_{2} \mathrm{~S}$ production. Lecithinase production was demonstrated in egg-yolk medium (Difco). A positive lecithinase reaction was indicated by an opaque zone in the medium around the colonies.

Ammonia from arginine ( $10 \%, \mathrm{w} / \mathrm{v}$, added to PY medium) was detected by Nessler's solution. Voges-Proskauer and the methyl-red tests were done in PYG medium without resazurin according to Cowan \& Steel (1970). All of the test media were semi-solid $(0.1 \%, w / v$, agar) and poured into screwcapped tubes, except for the egg-yolk and starch media and the Rogosa-SL medium (Difco) which were solidified with $2 \%(\mathrm{w} / \mathrm{v})$ agar and prepared in plates. All plates were stored anaerobically until inoculated, after which they were immediately incubated in anaerobic GasPac jars.

Acid production from carbohydrates was tested in a basal semi-solid PRAS PY medium. Carbohydrates were added to this basal medium at concentrations of $\mathrm{I} \%(\mathrm{w} / \mathrm{v})$, except for arabinose, adonitol, glycogen, ribose and trehalose which were added at $0.5 \%(\mathrm{w} / \mathrm{v})$. Media were poured into $\mathrm{CO}_{2}$-gassed screwcapped tubes. Syringe-inoculated tubes were incubated for 5 days at $37^{\circ} \mathrm{C}$ and acid production was detected by determining the $\mathrm{pH}$ directly in the tubes with a pH meter (Radiometer AS, Copenhagen, Denmark). $\mathrm{pH}$ values below 5.7 were recorded as positive. Weak acid production ( $\mathrm{pH} 5.8$ to 5.9) was considered negative since the $\mathrm{pH}$ of uninoculated PRAS PYG media containing arabinose, ribose and xylose was found to be about $6 \cdot 0$ to $6 \cdot 2$ after standing $I$ to 2 days in the $\mathrm{CO}_{2}$ atmosphere.

Analyses of bacterial metabolic end-products from glucose fermentation were studied in a 5-day-old PYG broth culture containing $5 \mathrm{~g}$ glucose/l. Ether extraction and methylation of acidic metabolic components from the culture were performed as described by Holdeman and Moore (Anaerobe Laboratory Manual, 1973). The results obtained from gas-liquid chromatography on two different instruments were compared. A Varian Aerograph model 940 (Varian Associates, California, U.S.A.), equipped with a hydrogen-flame ionization detector, employed a $5 \mathrm{ft} \times \frac{1}{8}$ in outer diameter stainless-steel column containing $10 \%$ (w/w) FFAP (Applied Science Laboratory, Incorporated, Pennsylvania, U.S.A.) on 
I00/I20 Varaport. The operation parameters of the instrument were as follows: injectionport temperature $200{ }^{\circ} \mathrm{C}$, detector temperature $200{ }^{\circ} \mathrm{C}$, column-oven temperature II $5{ }^{\circ} \mathrm{C}$. The carrier gas was $10 \mathrm{ml}$ nitrogen $/ \mathrm{min}$, and a $3.0 \mu \mathrm{l}$ sample containing the test substance was injected into the instrument. The other instrument was a Varian Aerograph model 920 fitted with a thermal-conductivity detector. A $5 \mathrm{ft} \times \frac{1}{4}$ in stainless-steel column packed with $5 \%(w / w)$ FFAP on Cromosorb G 70/80 AM-DMCS was used. The operating temperatures for the injector, detector and column were 200,160 and $120^{\circ} \mathrm{C}$, respectively. The carrier gas was $50 \mathrm{ml}$ helium $/ \mathrm{min}$, and a $15 \mu \mathrm{l}$ sample was injected. An uninoculated PYG-medium blank was tested to detect the presence of contaminating acids. If acids were present in significant quantities the medium was discarded, but if there were only trace amounts the blank was subtracted from the culture results. Identification was achieved by comparing the retention times of fermentation products with those of standard mixtures. Formic acid was not detected by the gas-chromatograph equipped with a flame-ionization detector.

Computer analysis. The data were analysed by using a numerical taxonomy program written for an IBM II 30 computer. Characters existing in one of two mutually exclusive states were coded"in binary form (o and I) for computation. Quantitative multi-state characters were converted into two-state characters using the additive coding method (Sneath, 1957). Thus, the results were coded in 90 character states. Nineteen of these gave identical results and were deleted from the computation. All strains were Gram-positive and did not form square-ended cells. No colonies exhibited an eroded or fimbriated margin. All strains grew anaerobically in PRAS PYG medium at $37^{\circ} \mathrm{C}$. No strain produced isobutyric, valeric, isocaproic, heptanoic, pyruvic, oxalacetic, oxalic, methyl malonic or fumaric acid from glucose in PRAS PYG broth. Thus, the final $n \times t$ matrix contained 7 I character states and I 2 strains or operational taxonomic units (o.t.u.s).

The phenetic resemblance for each pair of o.t.u.s was calculated in two ways: by the similarity coefficient $\left(S_{\mathrm{J}}\right)$ (Sneath, I957), in which negative similarities are excluded; and by the simple matching index $\left(S_{\mathrm{SA}}\right)$ (Sokal \& Michener, 1958), in which negative similarities are included. The percentage difference between strains was estimated by calculating the vigour difference, $D_{\mathrm{V}}$, and the pattern difference, $D_{\mathrm{P}}$, as devised by Sneath (1968). The confidence limits of the resemblance coefficients were estimated as the sum of the effects on the similarity coefficient of the experimental error (Sneath \& Johnson, 1972) and the sampling error (Goodall, 1967). The single-linkage cluster analysis (SLCA) (Sokal \& Sneath, 1963) and the unweighted pair group method using arithmetic averages (UPGMA) (Sokal \& Michener, I958) were employed for clustering. The co-phenetic correlation technique (Sokal \& Rohlf, 1962) was used to calculate the agreement between the similarity and dissimilarity matrices and the dendrograms derived by the SLCA and UPGMA clusterings. The homogeneity of the defined clusters (phena) and the inter-relationships between them were determined by calculating the intra- and inter-group similarity values. The differences between the phena due to variations in total metabolic activity, as measured by the number of positive reactions, were analysed by calculating the mean, range and standard deviation of vigour values and by estimating the spread between the phena. The effect of vigour on the phenetic relationships between strains was estimated by clustering on the $D_{\mathrm{P}}$ coefficients matrix by SLCA and UPGMA and comparing the relationships of strains with those obtained by clustering on the similarity coefficients. The frequency of occurrence of the characters in the 'natural' polythetic groups (phena) was tabulated. A 'calculated median organism' (c.m.o.) for each phenon equivalent to species rank was calculated according to Liston, Weibe \& Colwell (I963), and the dimensions of the taxospecies were calculated as a measure of the phenetic variation of the taxa. 
The range of variation within a taxospecies was obtained by assuming that the similarity values of the strains to the c.m.o. showed a normal distribution curve around the mean similarity value to the c.m.o. It was further expected that $95 \%$ of the members of a phenon would be allocated within the mean similarity value \pm twice the standard deviation (Gyllenberg, 1965). The lowest permissible similarity index for a strain to be included in a particular species was established.

Distinguishing and determining features, suitable for providing an identification scheme, were selected by comparing the total array of characters for each defined cluster of strains. A differential weighting of characters for the construction of a diagnostic table was performed on the basis of their constancy within the taxa, with frequencies in the taxa of less than $10 \%$ or above $90 \%$.

Immunofluorescence studies. Immunofiuorescent staining of pure cultures was used to check the computed strain clusters. Monospecific and fractionated fluorescein-isothiocyanate (FITC)-labelled rabbit IgG or $\mathrm{F}\left(\mathrm{ab}^{\prime}\right)_{2}$-fragments of the $\mathrm{IgG}$ antibodies were prepared against $A$. viscosus serotype I (ATCC I 5987), A. viscosus serotype 2 (ATCC 19246), A. naeslundii (ATCCI 2 104), $A$. odontolyticus serotype I (ATCCI 7982), A. odontolyticus serotype 2 (WvU482), $A$. israelii serotype I (ATCCI2 I03), A. israelii serotype 2 (WVU307), Ar. propionica serotype I (ATCCI4I57), Ar. propionica serotype 2 (WvU346), Actinobacterium meyerii (VPI86I7), Propionibacterium acnes serotype I (NCTC737) and P. acnes serotype 2 (ATCCI1828). All conjugates exhibited the physicochemical and performance characteristics outlined by Holmberg \& Forsum (1973). Smears were stained and the results recorded as detailed in the same report. All smears were read under a Zeiss fiuorescence microscope equipped with an Osram HB200 mercury lamp, an oil-immersion dark-field condenser, and a combination of a $4 \mathrm{~mm}$ BG 12 primary filter and a Zeiss 50 secondary filter.

\section{RESULTS}

\section{Clusterings of the strains}

The results of the computation are presented in a dendrogram (Fig. I), derived by SLCA of the sorted matrix calculated by using the $S_{\mathrm{SM}}$ matching coefficient. The co-phenetic correlation was 0.89 . Ninety-four of I I 2 strains $(84 \%)$ were assigned to one of six main clusters (phena) recognized at the range of 85 to $88 \%$ similarity level (Table 2). The phena were given the names of the numerically dominant reference strains found within the clusters. Thus, three of the major phena could be equated with the genera Bifidobacterium, Arachnia and Propionibacterium. In one of the remaining phena, reference strains of the facultative anaerobic Actinomyces species, $A$. viscosus, $A$. naeslundii and $A$. odontolyticus, were grouped. The other two phena contained named strains of $A$. israelii and Act. meyerii, respectively.

Phenon I: the Bifidobacterium cluster. This cluster contained twelve new isolates from faeces, dental plaques and dentin caries, and all the reference strains of Bifidobacterium species except $B$. bifidum. Three sub-clusters are discernible. Within one of the sub-clusters, the reference strains of $B$. longum formed a distinct subgroup with four strains $(88,94,95$ and 96) isolated from faeces. Within one of the other sub-clusters, the reference strains of $B$. adolescentis var. b, $B$. dentium and $B$. eriksonii formed a subgroup together with two new isolates, one from dental plaques (80) and one from dentin caries (Be I 8). Two strains (57 and 58 ) isolated from dental plaques, and the reference strains $B$. adolescentis var. d, $B$. parvulorum and $B$. infantis, were joined in a subgroup at $91 \%$ similarity. The remaining reference strains and isolates did not form subgroups but were linked to the sub-clusters at the $89 \%$ similarity level. 


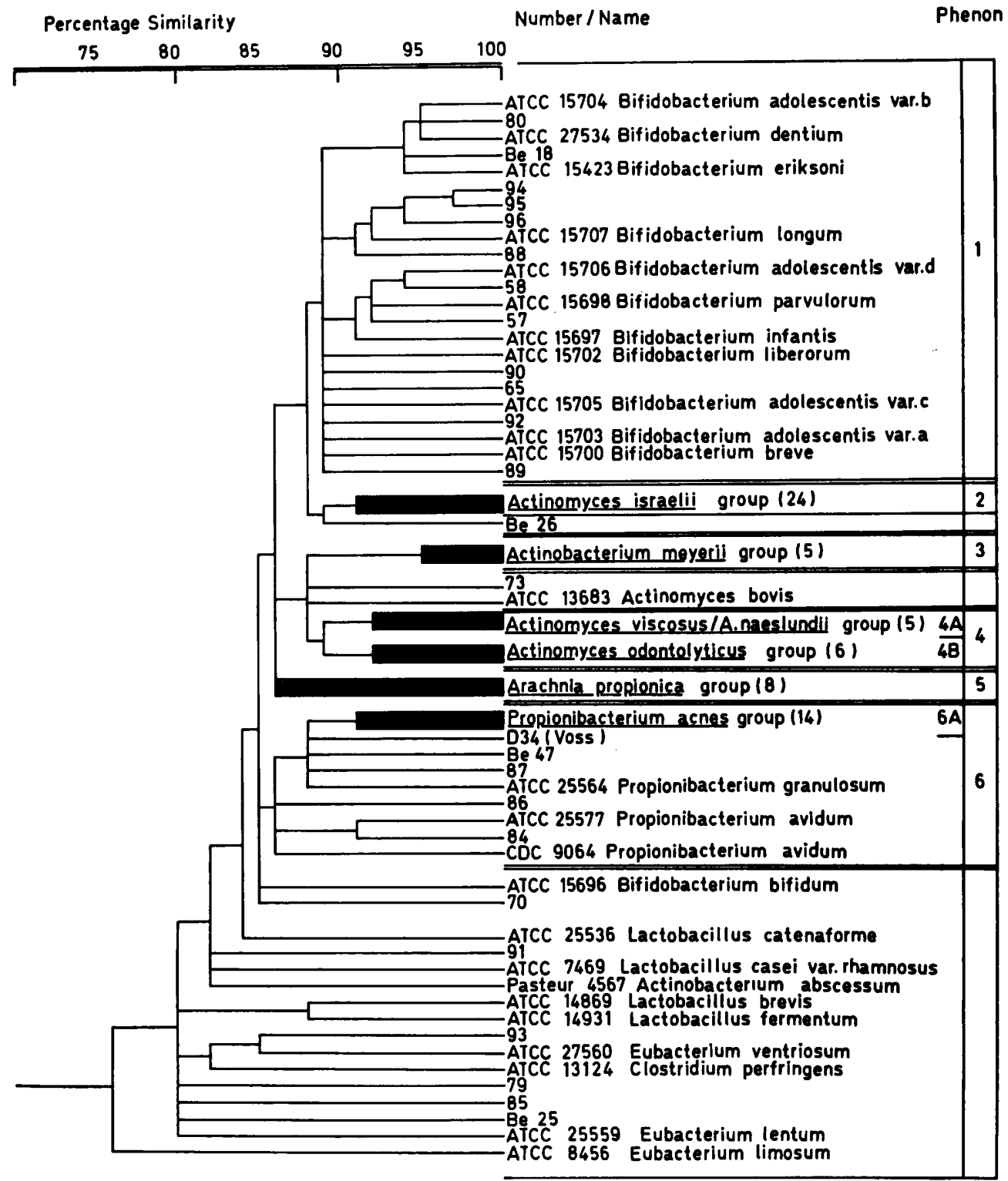

Fig. I. Simplified dendrogram of relationships between the main phena formed by SLCA on $\mathbf{S}_{\mathrm{SM}}$. The top of a filled column represents the lowest similarity at which any branch arises among the strains in the phena.

Phenon 2: the Actinomyces israelii cluster. Six new isolates from dental plaques and i8 reference strains joined above the $9 \mathrm{I} \%$ similarity level to form a tight cluster. A further strain, Be26, joined this phenon at $89 \%$ similarity.

Phenon 3: the Actinobacterium meyerii cluster. Five reference strains, designated Act. meyerii, formed a tight cluster at the $94 \%$ similarity level.

Phenon 4: the facultative anaerobic Actinomyces cluster. This cluster consisted of II strains. Two distinct and contrasting sub-clusters, $4 \mathrm{~A}$ and $4 \mathrm{~B}$, were defined at the $92.5 \%$ 


\section{Table 2. Strains of the major groups (phena)}

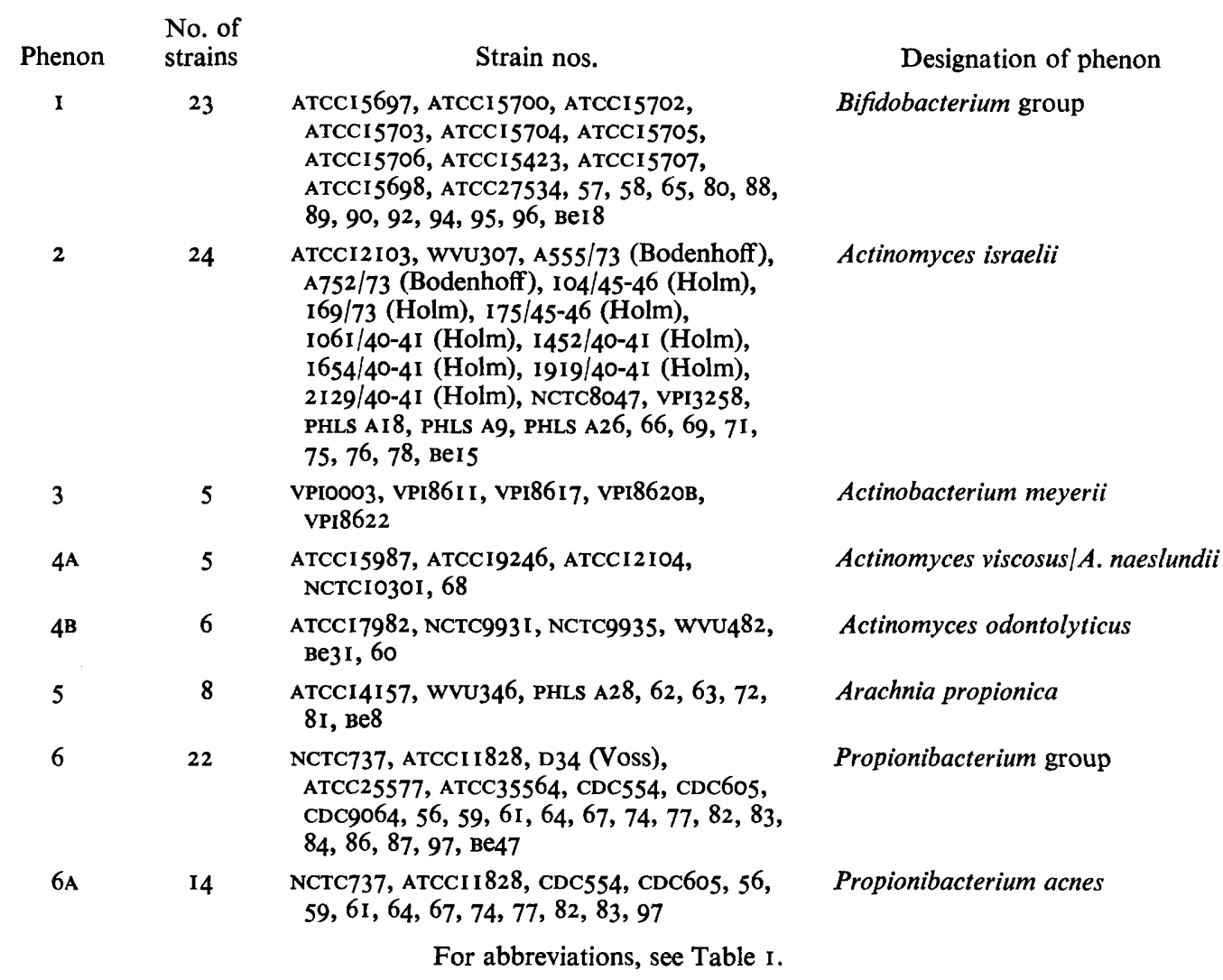

similarity level or above. Sub-cluster 4A comprises the four reference strains of Actinomyces viscosus and $A$. naeslundii, and one isolate from dental plaques. Included in sub-cluster $4 \mathrm{~B}$ were the four reference strains of $A$. odontolyticus, one isolate from dentin caries and one from dental plaques. Isolate 73 , and the reference strain $A$. bovis ATCC1 3863 , fell just outside phenon 4.

Phenon 5: the Arachnia cluster. This cluster represented Arachnia propionica. It contained the three reference strains received as Ar. propionica, four isolates from dental plaques and one strain isolated from carious dentin, Be8. They formed a phenon at the $87 \%$ similarity level.

Phenon 6: the Propionibacterium cluster. This cluster contained 22 strains. Isolates from faeces, dental plaques and carious dentin, and the reference strains received as Propionibacterium spp., were represented. A sub-cluster, 6A, included the reference strains of $P$. acnes and ten isolates which coalesced above the $91 \%$ similarity level. A Propionibacterium strain received as Corynebacteruim acnes group 2 (Voss D34), and the reference strain of $P$. granulosum (ATCC25564) were included at the periphery of this sub-cluster. The other strains, including named strains received as $P$. avidum (ATCC25577 and CDC9064) were linked at the $87 \%$ similarity level.

The ungrouped strains. Five strains isolated from plaques and faeces, and one strain isolated from dentin caries, could not be assigned to any of the main clusters defined at the 


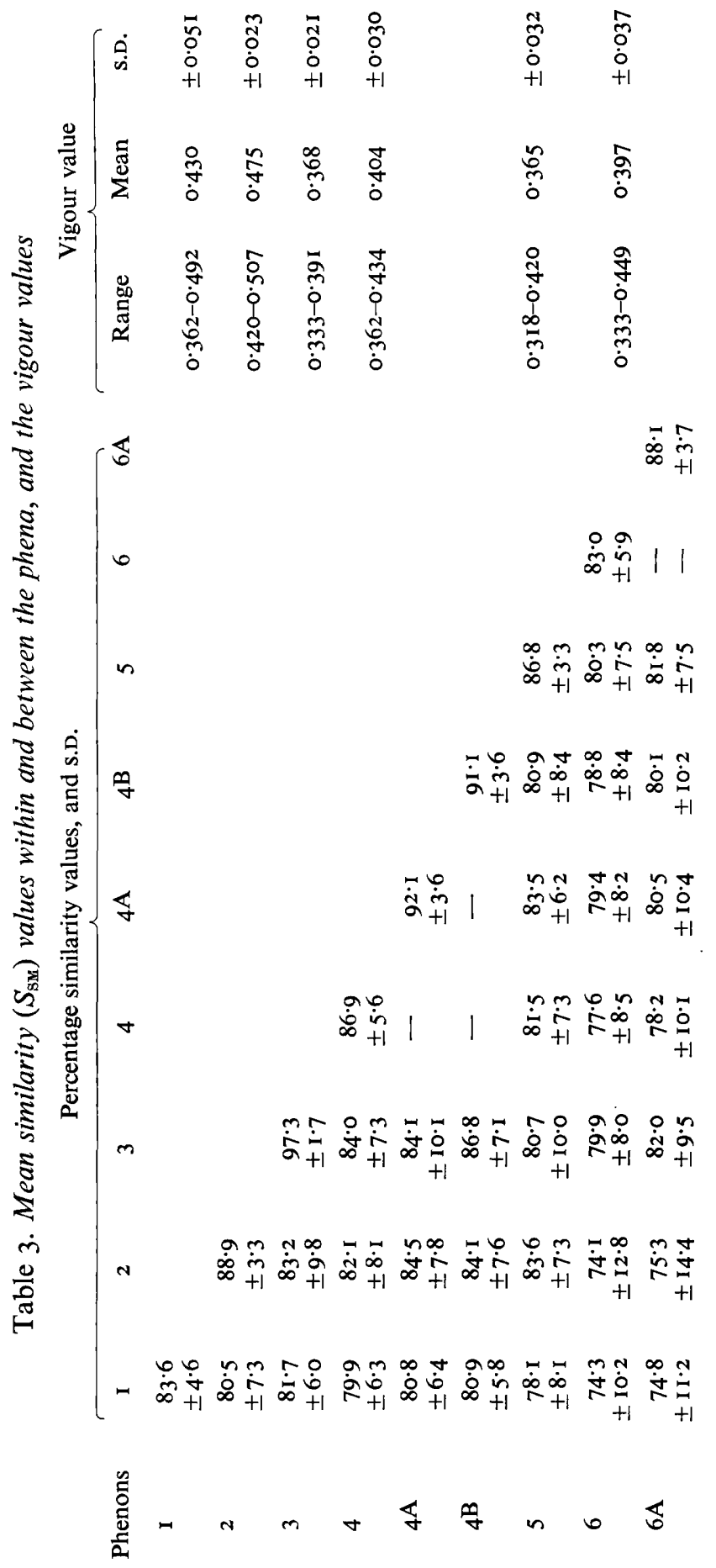




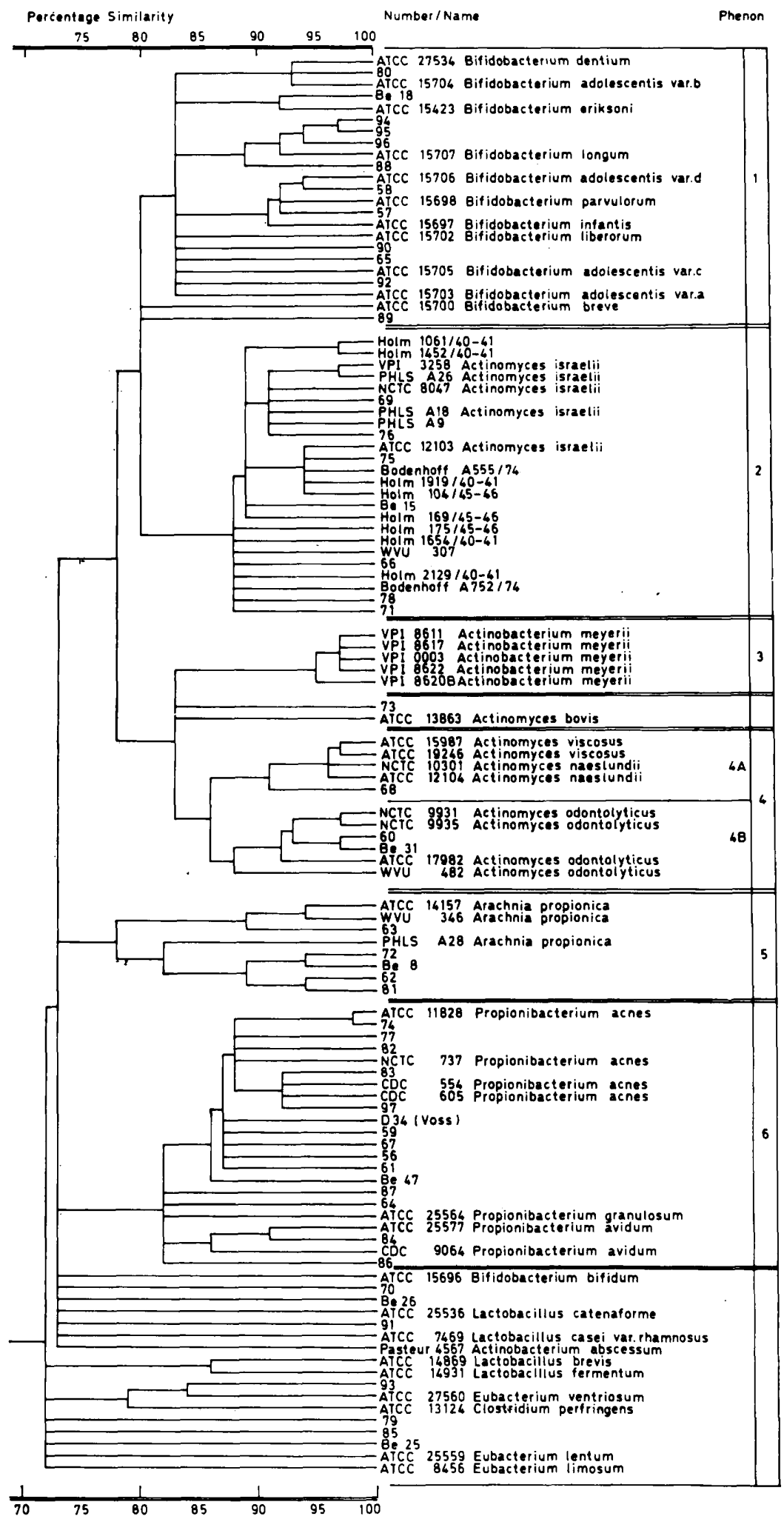

Fig. 2. Dendrogram of relationships within and between phena formed by UPGMA clustering on $\mathbf{S}_{\mathrm{SM}}$. 
$86 \%$ similarity level or above. The reference strains of the genera Lactobacillus and Eubacterium, and the reference strains of B. bifidum (ATCCI5696), Actinobacterium abscessum (Pasteur 4567) and $\mathrm{Cl}$. perfringens (ATCC13124), were also ungrouped.

The mean and the standard deviations of the intra- and inter-group similarity values of the defined phena are presented in Table 3. The range, mean and standard deviations of the vigour values are shown in the same Table. The differences in vigour between the major phena were small. The highest value is shown by $A$. israelii and the lowest by Act. meyerii, but the spread was not great. Clustering on $D_{\mathrm{P}}$, the pattern difference coefficient, by SLCA gave results very similar to that obtained by clustering with SLCA on the similarity values $\left(S_{\mathrm{SM}}\right)$.

\section{Comparison of data by means of different resemblance coefficients and cluster analysis techniques}

The taxonomic relationship derived from the $S_{\mathrm{SM}}$ matrix by an unweighted average linkage (UPGMA) clustering was very similar (Fig. 2). The co-phenetic coefficient was 0.92 and the dendrogram revealed few additional points of interest. Ninety-three of the II 2 strains were assigned together at the $78 \%$ similarity level. The isolate Be 26 was now ungrouped. The six main phena defined by SLCA were recovered and delineated at the 78 to $83 \%$ similarity level. They included the two sub-clusters $4 \mathrm{~A}$ and $4 \mathrm{~B}$ of the facultative anaerobic Actinomyces cluster (4). In contrast, the sub-cluster P. acnes (phenon 6A) was not recovered in its entirety. The strain D34 (Voss) was now included in this sub-cluster, whereas the isolate 64 was unplaced. The strain Be 47 was placed at the periphery of the subcluster 6A. In addition, the type strain of B. eriksonii (ATCCI 5423) and the isolate BeI 8 were more distinctly separated from the subgroup containing the strains of $B$. adolescentis var. $\mathrm{b}$ and $B$. dentium.

A similarity matrix of coefficients was produced based on the similarity index, $S_{\mathrm{J}}$, which only scores positive matches. The dendrograms produced by SLCA and UPGMA clustering from this similarity matrix revealed the six main phena. They were delineated as distinct clusters at the $78 \%$ similarity level.

\section{Characters of the defined phena}

The major phena shared a series of salient and almost invariable properties (Table 4). All strains were non-motile, Gram-positive non-sporeforming irregular rods, often pleomorphic with club-shaped ends and dichotomous branching. All strains grew anaerobically in an oxygen-free $\mathrm{CO}_{2}$ atmosphere in PRAS PYG medium, giving small ( $<2 \mathrm{~mm}$ diam) rough or smooth convex colonies that were opaque, and commonly white or off-white to grey. All strains were fermentatively active and fermented glucose with the formation of acidic metabolic end-products.

All Bifidobacterium strains of phenon I formed irregular branched elements with clubshaped ends, and showed dichotomous or multiple branching. The colonies were smooth, and raised or convex, with entire or crenate margins. No strains grew under aerobic conditions. All strains hydrolysed starch but were unable to reduce nitrate. The fermentative pattern included the production of acid from galactose, lactose, raffinose and ribose. The end-products from glucose fermentation were acetic and lactic acids, approximately in the ratio I 5 to I 0 . Some strains also produced succinic acid.

The $A$. israelii strains of phenon 2 showed markedly pleomorphic elements varying from cocco-bacillary to irregular rods in filamentous arrangement with rounded or club-shaped ends. The colonies were convex and rough with crenate margins, and mostly white or off- 
Table 4. The characters of the major phena $A$. viscosus/A. naeslundii, A. odontolyticus, A. israelii, Act. meyerii, Ar. propionica and P. acnes, expressed as percentages of the strains exhibiting that character

Character

Cell morphology

Coccus (spherical)

Cocco-bacillary

Regular rods

Irregular rods

Dichotomous

Multiple branching

Pleomorphic

Square-ended elements

Round-ended elements

Club-shaped ends

Tapered elements

Fusiform elements

Gram stain reaction negative

Gram stain reaction positive

Gram stain reaction variable

Single elements

Paired elements

Filaments

Variable arrangement

Colony morphology

Size $(\mathrm{mm})$

$$
\begin{array}{r}
<2 \\
2-5
\end{array}
$$$$
>5
$$

Flat (effuse)

Raised

Convex

Umbonate

Entire margin

Crenate margin

Erose margin

Fimbriate margin

Transparent

Opaque

White

Off-white to grey

Colour

Rough

Smooth

Mucoid

Growth

Aerobic

$$
\begin{array}{r}
+ \\
++ \\
++
\end{array}
$$

Anaerobic

$$
\begin{array}{r}
+ \\
++ \\
++
\end{array}
$$

On Rogosa's agar

At $45^{\circ} \mathrm{C}$

At $37^{\circ} \mathrm{C}$
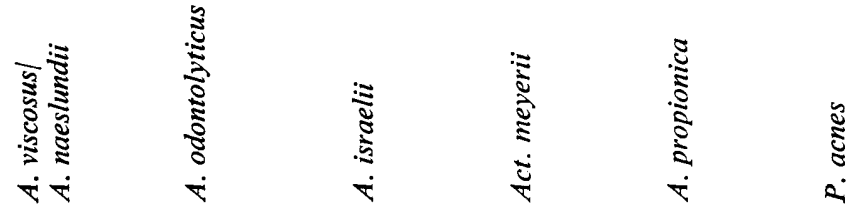

0
100
0

0

33
4

4
100

100

0

20

100

0

100

0

100

0

0

100

0

100

0

IOO

50
100

100
50

0

100

0

I7

I 7

0

0

100

0

100

0

50

100

\section{6}

2 I

96

0

96

2 I

33

33
0

0

100

0

82

4
58

100

0

13

100

0

100
0

100

o

0

100

IOO

0

100

0

100

0

100

0

100

0

100

0

0
75

75
0

0
100

I0O

88

0

0
100

0

88

0

100

43
$\mathrm{o}$

100

0

o

o

IOO

14

100

0

100

0
100

7

IOO

100

0

100

100

13
0

IOO

100

93

0

0

43

0

100

100

0
100

100

0
$I 00$

0

4

0
79

80

0

80

20

o

o

I

100
0

100

0

0
100

100

100

I0O

100

0
100

0
25

100

0

0
4

100

25

75

0
96

96
4

0
0
0
0
100
0
80
0
0
100
0

0
100

75

0

0
100

25

75

0

50

50

$$
0
$$

o

0

100

36

I4

64

0
100

7

$\begin{array}{rr}13 & 0 \\ 0 & 7 \\ & 0 \\ 100 & 100 \\ 100 & 100 \\ 100 & 100 \\ 0 & 0 \\ 13 & 43 \\ 100 & 100\end{array}$


Table 4 (cont.)

Biochemical tests

Aesculin hydrolysis

Gelatin liquefaction

Indole production

Nitrate reduction

Catalase production

Arginine reduction

Voges-Proskauer test
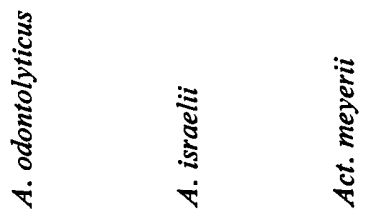

$\frac{\text { \} }{3}}{}$

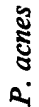

Methyl-red test

$\mathrm{H}_{2} \mathrm{~S}$ production

Starch hydrolysis

Lecithinase production

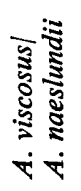

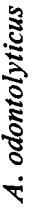
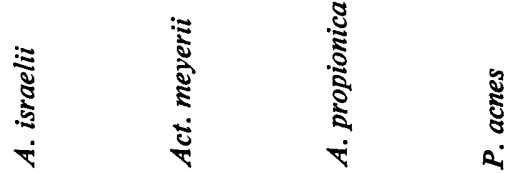

Acid production from:

Arabinose

Galactose

Mannose

Xylose

Glucose

Ribose

Lactose

Trehalose

Raffinose

Glycogen

Adonitol

Mannitol

Sorbitol

$\begin{array}{rr}100 & 49 \\ 0 & 0 \\ 0 & 0 \\ 100 & 100 \\ 40 & 0 \\ 20 & 17 \\ 0 & 0 \\ 40 & 0 \\ 0 & 17 \\ 40 & 17 \\ 0 & 0\end{array}$

100

o

0

I00

0

96

0

0100

4

75

17

$\begin{array}{rr}0 & 17 \\ 80 & 100\end{array}$

42
67

100
0

0
83

$100 \quad 100$

100

End-products from glucose

Acetic acid

Propionic acid

Isobutyric acid

Buryric acid

Isovaleric acid

Valeric acid

Isocaproic acid

Caproic acid

Heptanoic acid

Pyruvic acid

Lactic acid

Oxalacetic acid

Oxalic acid

Methyl malonic acid

Malonic acid

Fumaric acid

Succinic acid

$\begin{array}{rr}100 & 0 \\ 0 & 0 \\ 0 & 0 \\ 0 & 0 \\ & \\ 100 & 100 \\ 0 & 0 \\ 0 & 0 \\ 0 & 0 \\ 0 & 0 \\ 0 & 0 \\ 0 & 0 \\ 0 & 0 \\ 0 & 0 \\ 0 & 0 \\ 100 & 100 \\ 0 & 0 \\ 0 & 0 \\ 0 & 0 \\ 0 & 0 \\ 0 & 0 \\ 100 & 100\end{array}$

$\begin{array}{rrr}60 & 0 & 0 \\ 100 & 50 & 79 \\ 0 & 100 & 93 \\ 100 & 0 & 0 \\ 100 & 100 & 100 \\ 100 & 25 & 50 \\ 100 & 13 & 7 \\ 0 & 100 & 0 \\ 0 & 63 & 0 \\ 80 & 0 & 0 \\ 0 & 0 & 7 \\ 0 & 100 & 7 \\ 0 & 13 & 64 \\ & & \\ 100 & 100 & 100 \\ 0 & 100 & 100 \\ 0 & 0 & 0 \\ 0 & 0 & 0 \\ 0 & 0 & 86 \\ 0 & 0 & 0 \\ 0 & 0 & 0 \\ 0 & 0 & 0 \\ 0 & 0 & 0 \\ 0 & 0 & 0 \\ 100 & 0 & 7 \\ 0 & 0 & 0 \\ 0 & 0 & 0 \\ 0 & 0 & 0 \\ 0 & 0 & 0 \\ 0 & 0 & 0 \\ 100 & 100 & 93\end{array}$

white to grey. They showed limited growth under aerobic conditions. Aesculin and arginine were hydrolysed and nitrate was reduced. They were fermentatively active, and acid was produced from mannitol, mannose, lactose, xylose, trehalose and ribose. Glucose was fermented with the production of acetic, lactic and succinic acids.

Strains of Act. meyerii in phenon 3 were all anaerobic. They formed pleomorphic elements including cocco-bacillary and irregularly-formed rods. The colonies were smooth, raised 
Table 5. The mean similarity value, and S.D., for members of the phena A. israelii, Act. meyerii, $A$. viscosus/A. naeslundii, A. odontolyticus, $A$. propionica and $P$. acnes, to their own c.m.o.

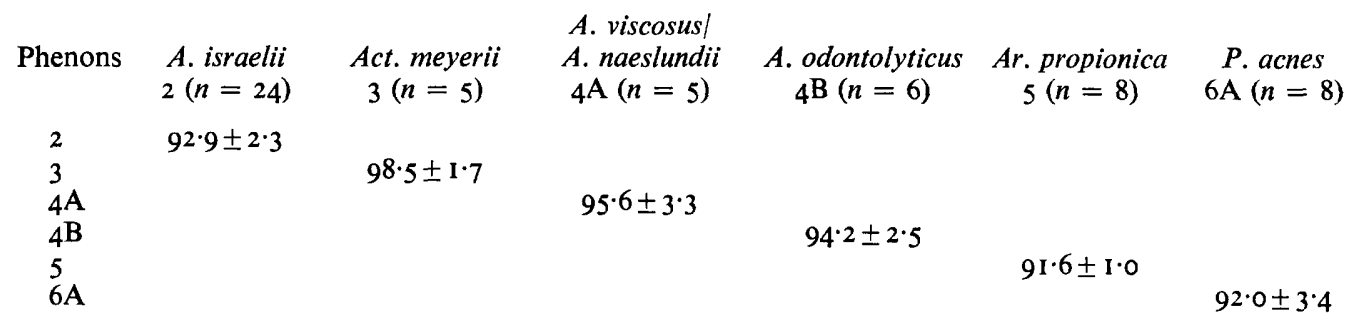

and convex, with an entire edge. Most colonies were off-white to grey. They reduced nitrate and gave a positive methyl-red test. Galactose, lactose, xylose and ribose were fermented. Acetic, lactic and succinic acid were produced from glucose.

Strains of $A$. viscosus and $A$. naeslundii of phenon $4 \mathrm{~A}$ were all facultative anaerobic and able to grow under aerobic conditions. They were irregular rods or cocco-bacilli, often pleomorphic with multiple branching, and produced smooth, convex, off-white to grey colonies with entire or crenate margins. They degraded aesculin and reduced nitrate. Acids were produced from mannose, lactose and raffinose. They fermented glucose with the production of acetic, lactic and succinic acid.

The $A$. odontolyticus strains in phenon $4 \mathrm{~B}$ had many morphological characters in common with the $A$. viscosus $\mid A$. naeslundii strains. They were able to grow aerobically after several subcultures in the laboratory. Nitrate was decomposed and acid formed from galactose and lactose. Acetic, lactic and succinic acids were produced from glucose.

The Ar. propionica strains in phenon 5 formed cocco-bacilli to irregular rods with a varying degree of branching; some strains also formed coccoid elements. They produced white or off-white to grey colonies which had many characters in common with $A$. israelii. Aesculin was not hydrolysed but nitrate was reduced. The fermentative pattern of these strains included acid formation from mannose, mannitol and trehalose. Glucose was fermented with the production of acetic, propionic and succinic acid.

The Propionibacterium strains in phenon 6 formed irregular rods and tapered elements with rounded ends in variable arrangements. The colonies were smooth and convex with entire margins. The colonies were opaque, and either white or off-white to grey or pink. The strains showed no distinctive biochemical or fermentative properties. However, all strains fermented glucose with the production of acetic and propionic acid and most strains also produced isovaleric acid. The $P$. acnes strains in phenon 6A were less variable in their biochemical reactions (Table 4). All strains produced catalase and indole, reduced nitrate but failed to hydrolyse aesculin.

\section{Calculation of phenetic variation within the defined phena}

In Table 4 are shown the percentages of positive results in the major phena from which the hypothetical 'calculated median organisms' (c.m.o.s) were calculated. Table 5 gives the mean similarity values for the members of the phena to their respective c.m.o. The lowest permissible similarity index to the c.m.o., based on the simple matching coefficient that a carididate strain must possess to be included in the proposed taxospecies of $A$. viscosus $/ A$. naeslundii, A. odontolyticus, $A$. israelii, Act meyerii, Ar. propionica and $P$. acnes, can be 
calculated. The members of the phena showed consistently high similarity values to their respective c.m.o.s (Table 6). The new isolates, which in the numerical analysis appeared outside the major phena, exhibited similarity values to the created c.m.o.s falling outside a $5 \%$ range from the permissible low limits.

\section{Reproducibility of results}

An additional statistically designed experiment was performed in order to afford a check on experimental error in performing tests. The total array of tests was done in duplicate on the 26 new isolates from dental plaques representing members of all the defined phena. These tests were carried out on two separate occasions, employing the same medium, techniques and conventions for scoring. Twenty-eight of the tests gave identical results on both occasions in all the 26 strains. The least reproducible tests were on some morphological character states, anaerobic growth at $45^{\circ} \mathrm{C}$, hydrolysis from arginine, methyl-red test, $\mathrm{H}_{2} \mathrm{~S}$ production, starch hydrolysis and production of acid anaerobically from $\mathrm{I} \%(\mathrm{w} / \mathrm{v})$ raffinose. If the tests with identical results were excluded, the probability $(p)$ of an erroneous result averaged $3.12 \%$, equal to an observed value of $S_{\mathrm{SM}}$ of around $94 \%$ between subcultures of the same strains. The similarity value between the identical strains $I 452 / 40-4 \mathrm{I}$ (Holm) and VPI3258 was $95.6 \%$, between ATCCI 2104 and NCTCIO3OI $94.2 \%$, and between ATCCI 7982 and NCTC993I was $92 \cdot 3 \%$, as calculated by the simple matching coefficient $\left(S_{\mathrm{sx}}\right)$.

Gas chromatographic analyses by two instruments with different operating conditions on the same sample gave identical results with respect to the qualitative interpretation of the metabolic end-products produced in glucose fermentation.

\section{Identification by immunofluorescence}

In direct immunofluorescence, all new isolates and reference strains which in the numerical analysis were grouped within the phena of $A$. israelii, Act. meyerii, A. viscosus/A. naeslundii, $A$. odontolyticus, Ar. propionica and $P$. acnes, exhibited positive immunofluorescent reactions with species-specific conjugates to the type strains of the respective species (Table 6). All other strains were negative to these conjugates in immunofluorescence, but there was one aberrant result - the indole-producing strain 87 , which appeared peripheral to the $P$. acnes cluster, showed a positive reaction with anti-P. acnes serotype I (NCTC737) serum.

The strains in the phena of $A$. viscosus/A. naeslundii, A. odontolyticus and Ar. propionica provided no correlation between phenotypic characteristics and serotype. Strains allocated to the phenon of $A$. viscosus/A. naeslundii showed positive immunofluorescent staining to A. viscosus serotype I (ATCCI 5987), A. viscosus serotype 2 (ATCCI 9246) or A. naeslundii (ATCCI2104) antisera.

\section{Diagnostic table}

Each defined phenon was examined for distinguishing features that could be weighted for identification. By comparing the frequencies of occurrence for the total array of characters within each defined phenon a diagnostic table could be constructed for the differentiation and identification of A. viscosus/A. naeslundii, A. odontolyticus, Act. meyerii, A. israelii and $A r$. propionica from the related propionibacteria and bifidobacteria (Table 7). In the case of propionibacteria, characters were also devised for the identification of Propinibacterium acnes. 

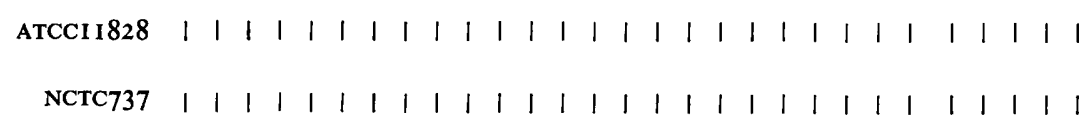

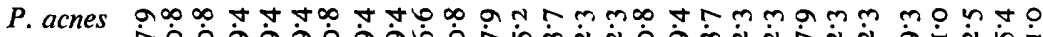

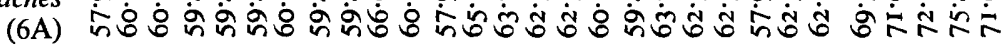

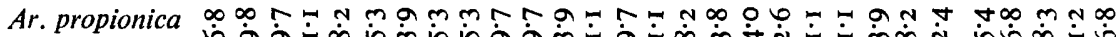

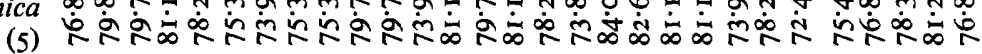

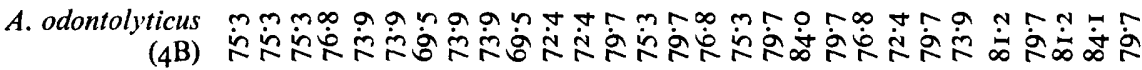

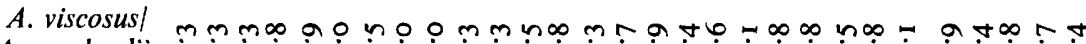

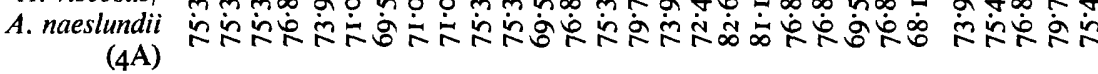

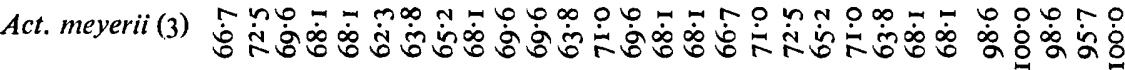

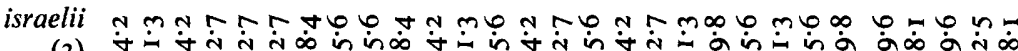

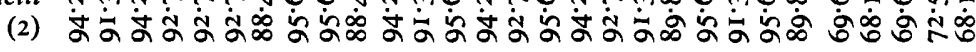

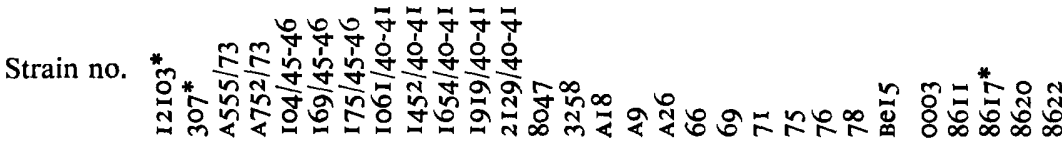




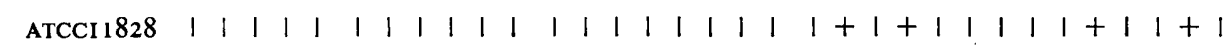

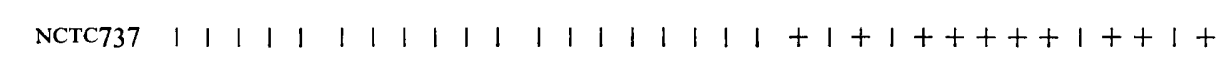

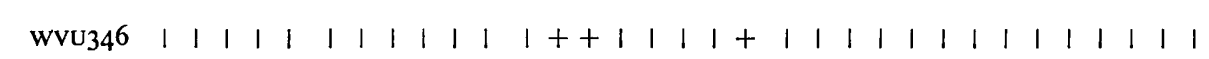

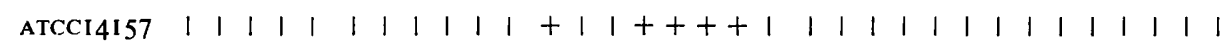

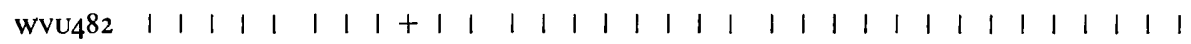
$\operatorname{ATCC} 1982 \quad 1 \quad 1 \quad 111+t+1++\begin{array}{lllllllllllllllllllllll}1 & 1 & 1 & 1 & 1 & 1 & 1 & 1 & 1 & 1 & 1 & 1 & 1 & 1 & 1 & 1 & 1 & 1 & 1 & 1 & 1 & 1\end{array}$

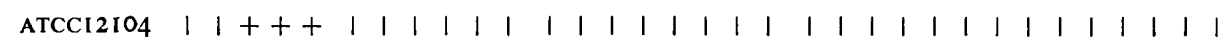

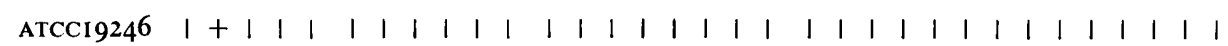
$\operatorname{ATCC} 5987+111111111111111111111111111111111$ $\begin{array}{lllllllllllllllllllllllllllllllllll}\text { VPI8617 } & \mid & 1 & 1 & 1 & 1 & 1 & 1 & 1 & 1 & 1 & 1 & 1 & 1 & 1 & 1 & 1 & 1 & 1 & 1 & 1 & 1 & 1 & 1 & 1 & 1 & 1 & 1 & 1 & 1 & 1 & 1 & 1 & 1\end{array}$

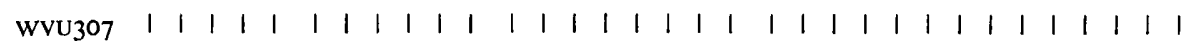
$\begin{array}{llllllllllllllllllllllllllllllllllll}\operatorname{ATCC} 12 & 103 & 1 & 1 & 1 & 1 & 1 & 1 & 1 & 1 & 1 & 1 & 1 & 1 & 1 & 1 & 1 & 1 & 1 & 1 & 1 & 1 & 1 & 1 & 1 & 1 & 1 & 1 & 1 & 1 & 1 & 1 & 1 & 1 & 1\end{array}$

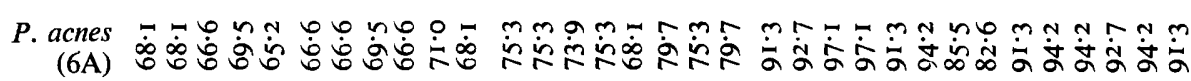

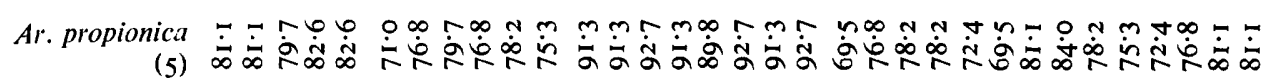

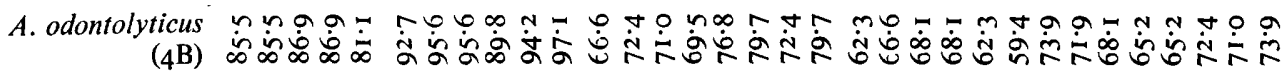
A. viscosusl -

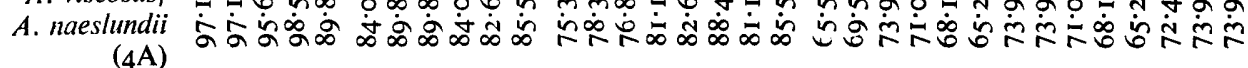

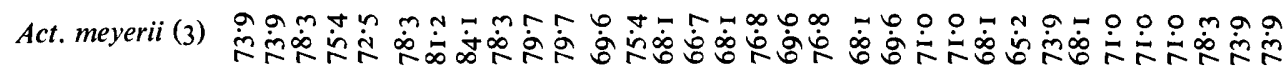

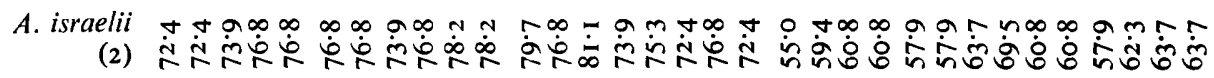

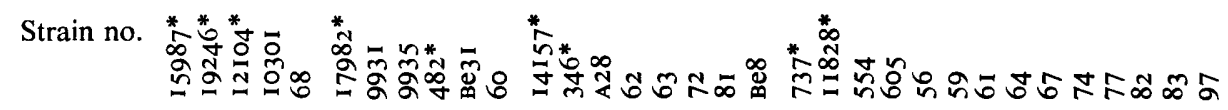
Phenon $\Varangle \quad \forall$ in 


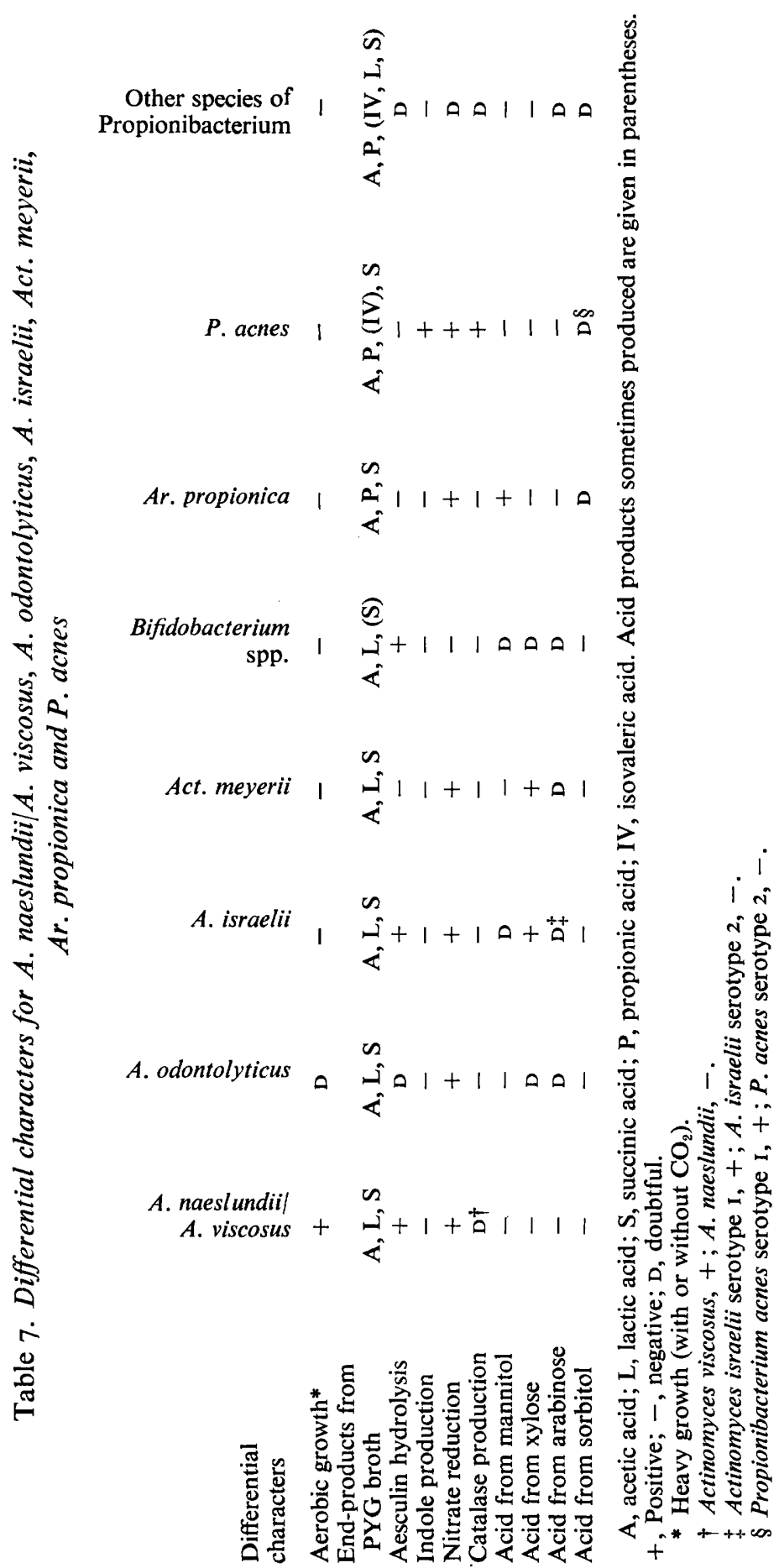




\section{DISCUSSION}

Most new isolates of facultative anaerobic and obligate anaerobic Gram-positive filamentous and/or diphtheroidal organisms and the reference strains of predictor genera were distributed in one of six clusters. By comparison with the current taxonomic views (Prévot, 1966; Pine, I970; Cross \& Goodfellow, 1973) of the actinomycetes and the allocation of the included marker strains, the taxonomic rank of these clusters would be appropriately accepted as equivalent to generic taxa of Actinomyces, Arachnia, Actinobacterium, Bifidobacterium and Propionibacterium. These defined clusters (phena) appeared to be valid. There was good consonance of the clusters formed by the single linkage and by the unweighted average linkage cluster methods on the resemblance coefficients, and the homogeneities of the phena were high as measured by the intra-group mean similarity values.

There is always a danger with numerical classification that taxonomic groups are influenced by differences in growth rates and cultural conditions (Sneath, I968). This is particularly true with the facultative anaerobic Actinomyces species and the anaerobic $A$. israelii and Ar. propionica which differ in the rate of growth (Pine, 1970). The differences observed between the phena of these organisms appeared not to be due to unequal growth rates. The uniform mean vigour values of the phena indicated that comparison was made between clusters that were equally vigorous, i.e. their ability to carry out varied metabolic activities was about the same as measured by the number of positive reactions in the tests employed. Reading the tests at a specified time, after exactly five days of incubation at $37^{\circ} \mathrm{C}$ for fast-growing as well as slow-growing strains, had the effect of reducing the introduction of phenetic dissimilarities due to unequal growth rates, since it is uncommon for positive tests to revert to negative on continued incubation. Similar considerations apply to an accurately-controlled atmosphere for incubation, since variations in the degree of anaerobiosis might have the effect of changing metabolic activity. This difficulty was overcome by assembling all data on phenotypic characters from tests performed under strict anaerobiosis. On the other hand, the work by Melville (1965) with facultative anaerobic actinomycetes suggests that the phenetic resemblances are much the same, whether they are grown aerobically or anaerobically.

The influence of the reproducibility of tests on similarity values was recently discussed by Sneath \& Johnson (1972). The estimated probability of an incorrect test averaged $3 \%$ over the set of tests employed in the present study, if the time of reading was specified as 5 days of incubation at $37^{\circ} \mathrm{C}$. This amount of experimental error in the similarity values has in practice been found acceptable in numerical taxonomic studies (Sneath \& Johnson, I972; Sneath, 1972). The level of similarity of 93 to $96 \%$, estimated between the replicate strains, is a confirmation of this opinion. However, the significance of the observed differences between the defined clusters has to be judged against the confidence limits of the similarity values, estimated as the sum of the experimental error and the sampling error of the 90 tests employed.

Among the major phena two clusters of Actinomyces strains equivalent to generic rank were recognized. One cluster contained the strains of $A$. israelii and the other the facultative anaerobic Actinomyces species including the representatives of $A$. viscosus, $A$. naeslundii and $A$. odontolyticus. The results throw doubts on the current taxonomic theory of a single genus Actinomyces, containing both the anaerobic and the facultative anaerobic Actinomyces strains. The anaerobic $A$. israelii cluster constituted a tight taxonomic entity quite distinct from other Actinomyces. Prévot (I96I) considered $A$. bovis and $A$. israelii to be sufficiently distinct to receive different generic names. He placed bovis in the genus Actinomyces and 
israelii in the genus Actinobacterium. The relatively simple carbohydrate component pattern of $A$. israelii walls compared with those of $A$. bovis, $A$. naeslundii, $A$. viscosus and A. odontolyticus (Boone \& Pine, 1968; DeWeese, Gerencser \& Slack, 1968; Pine, 1970) is also evidence of heterogeneity. Further work is needed to determine whether the $A$. israelii group deserves recognition as a separate genus within the family Actinomycetaceae.

Within the Actinomyces israelii phenon a second variant that failed to ferment arabinose was discernible as a distinct serotype by immunofluorescence. A second type of $A$. israelii is well documented and was first described by Holm (I930). The principle differences were that these variant strains gave viscous growth in liquid medium and failed to ferment arabinose (Holm, 1948; Brock \& Georg, I969b; Cummins, 1970). The separation of two variants of A. israelii has also been confirmed by serological methods (Lambert et al. 1967; Slack et al. I969; Brock \& Georg, I969a; Holmberg \& Forsum, I973; Holmberg, Nord \& Wadström, $1975 a, b)$ and by wall analysis (Cummins, 1970).

The facultatively anaerobic Actinomyces phenon was separated into two sub-generic groups which appeared to be acceptable taxospecies. One subgroup included the named strains of $A$. viscosus and $A$. naeslundii. It is well known that these organisms are phenetically close species, and this has recently been discussed by Holmberg \& Hallander (1973). Our present phenetic estimates on $A$. viscosus and $A$. naeslundii agree well with the results from this earlier numerical taxonomic work. They also confirm the close phenetic resemblance between these organisms under strictly anaerobic conditions in pre-reduced media. The type strains of $A$. odontolyticus (Batty, 1958) were found in the other sub-generic group of the facultative anaerobic Actinomyces phenon. The existence of a second serotype of $A$. odontolyticus (Slack \& Gerencser, 1970a) was verified by immunofluorescence, although it was not correlated to any specific phenetic properties. The recovery of the only strain of $A$. bovis that we studied in the facultative anaerobic Actinomyces cluster is consistent with the results of the numerical taxonomic study by Melville (1965) who recovered the type strains of $A$. odontolyticus in the $A$. bovis cluster.

The five strains received as Act. meyerii (Prévot, 1938, 196I, 1966, 1972) appeared to represent a phenotypically distinct group. Bouisset et al. (I968) noted that strains of Act. meyerii had guanine-cytosine base ratios that fall in the narrow range of 64 to 67 , close to those of Actinomyces (Actinobacterium) israelii and A. bovis. The strains of Act. meyerii examined in the present study were distinct by immunofluorescence, which provides further evidence for the segregation of these bacteria as a separate taxon. They appeared close to the Actinomyces so that they might be best associated with the Actinomycetaceae. Phenetically, they were closer to the facultative anaerobic Actinomyces than to $A$. israelii. This difference between Act. meyerii and $A$. israelii was not due to difference in the metabolic activity, since clustering on pattern results showed the same relationship between these organisms. The species Act. abscessum, of which we had only a single representative, did not fall into any defined cluster, which suggests that this species should not be allied with the Actinomycetaceae. The genetic study by Bouisset et al. (I968) supports this.

The genus Arachnia was set up by Pine \& Georg (1969) to accommodate propionateproducing bacteria with diaminopimelic acid in their wall, previously classified as Actinomyces propionicus (Pine \& Hardin, I959; Buchanan \& Pine, 1962). The phenotypic data presented here indicate that the Arachnia strains form a recognizable taxon, phenetically distinct from the other generic phena. This confirms serological (Georg et al. 1964; Gerencser \& Slack, I969; Holmberg \& Forsum, 1973) and genetic (Johnson \& Cummins, 1972) evidence which indicates that the strains of Arachnia form a reasonably homogeneous group. The differentiation of two variants of $A r$. propionica, previously proposed on the 
basis of wall composition and serological reactions, was confirmed by immunofluorescence.

The existence of a distinct generic phenon of bifidobacteria appeared to be justified on phenetic estimates. The separation of Bifidobacterium strains as a distinct group would support the recognition of bifidobacteria as a separate genus classified in the family Actinomycetaceae (Bergey's Manual of Determinative Bacteriology, 1974).

However, the Bifidobacterium cluster as it stands probably represents a heterogeneous mixture not clearly definable by the present taxonomic estimates. The recognition within the cluster of minor groups and single strains of named bifidobacteria and new isolates which joined at rather low similarity levels confirmed the existence of multiple species and species variants of human bifidobacteria (Dehnert, I957; Reuter, 1963, I97I; Mitsuoka, 1969; Scardovi et al. 1971). The data provide evidence for the existence of an additional group of mannitol-fermenting oral bifidobacteria, similar to the unassigned 'dentium' group of bifidobacteria proposed by Scardovi et al. (I97I), previously isolated from the human mouth by Beerens, Gérard \& Guillaume (I957) and designated as B. dentium (Scardovi \& Crociani, 1974).

The type strain of Bifidobacterium eriksonii (Georg et al. 1965) was allocated to the Bifidobacterium cluster. The strain was fermentatively similar to the bifidobacteria. The inclusion of this organism in the Bifidobacterium genus is strongly supported on this ground (Anaerobe Laboratory Manual, I973) although B. eriksonii has been reported to have the same qualitative wall component pattern as $A$. israelii serotype I (Boone \& Pine, I968). The type strains of $B$. bifidum (ATCCI5696) were not included in the phenon of Bifidobacterium and showed very little phenetic affinity with the other bifidobacteria.

A sufficiently distinct cluster was formed of Propionibacterium strains to warrant their designation as a separate genus. There has been much confusion concerning the genus Propionibacterium and disagreement on what should be considered valid species (Prévot, Turpin \& Kaiser, 1967; Moore, Holdeman \& Cummins, 1968; Zeirdt, Webster \& Rude, I968; Reid \& Joya, 1969). Recently, on the basis of nucleic-acid homology studies, Johnson $\&$ Cummins (1972) designated three major groups, $P$. acnes, $P$. avidum and $P$. granulosum. Propionibacterium acnes was further separated into two distinct types, based on the carbohydrate composition of the walls. In the present study the named strains of $P$. acnes fall into a sub-generic group which can be equated with a taxospecies. The boundary of this cluster was, however, rather diffuse. It is possible that strains of this cluster overlap with related species to a small extent or are phenetically intermediates, which would corroborate the reported phenetic heterogeneity of this species (Brzin, 1965; Puhvel, I968; Voss, I970; Pulverer \& Ko, 1973). The strain D34, received from Dr Voss as Corynebacterium acnes group 2 (Voss, 1970) was phenetically associated with $P$. acnes. The position is, however, not entirely clear because the strain showed negative reactions with mono-specific conjugates against both the serotypes of $P$. acnes, but positive immunofluorescence with mono-specific conjugate against the type strains of $P$. granulosum (ATCC25564). This type strain of $P$. granulosum appeared to be phenetically more similar to $P$. acnes than to $P$. avidum. The relationships between these species do not correlate consistently with genetic data, wall carbohydrate pattern (Johnson \& Cummins, 1972) and serological data obtained by immunofluorescence (Holmberg \& Forsum, 1973) on these organisms.

It is worth noting the taxonomic relationships found between the defined phena of Actinomyces, Arachnia, Propionibacterium and Bifidobacterium, since the question of the relationships of actinomycetes, propionibacteria and lactobacilli (bifidobacteria) has always been a vexatious problem (Puntoni, 1937; Prévot, 1938; Pine, 1970; Poupard, Husain \& 
Norris, 1973). It appeared that the Actinomyces, including Actinobacterium meyerii, showed a greater phenetic affinity to bifidobacteria than to propionibacteria. Pine \& Howell (1956) discussed the relationship of bifidobacteria to Actinomyces; they considered a major difference to exist between Actinomyces and the bifidobacteria, on the basis of the difference in the amounts of acetic and lactic acid produced. Pine (1970) concluded, in agreement with Snyder et al. (1967), that bifidobacteria are not serologically related to Actinomyces.

A somewhat higher average inter-group similarity to the Actinomyces clusters than to the Propionibacterium cluster suggests that the Arachnia strains should be classified within the Actinomycetaceae. The Arachnia strains, however, have several important characters in common with the propionibacteria, which suggest that they are intermediates between the families Actinomycetaceae and Propionibacteriaceae. Arachnia resemble propionibacteria in production of propionic acid and in the amino acid pattern of their wall peptidoglycan, but showed a low genetic similarity with these bacteria in DNA pairing studies (Johnson \& Cummins, 1972).

The numerical taxonomy resulted in natural groups which allowed the construction of a diagnostic table for the differentiation of $A$. israelii, $A$. viscosus, $A$. naeslundii, $A$. odontolyticus, Act. meyerii, P. acnes and Ar. propionica strains from the related bifidobacteria and propionibacteria. However, the present phenotypic information did not enable differentiation of other propionibacteria and bifidobacteria into species, and insufficient data were obtained to devise phenotypic characteristics for eubacteria and anaerobic lactobacilli. It was apparent that no single test could be selected that would differentiate Actinomyces and Arachnia from similar organisms or distinguish between different Actinomyces species. Identification of an unknown organism as an Actinomyces or Arachnia species has to be made on the results of a series of tests to provide specific means of identification. The diagnostic table was generated by means of a simultaneous strategy of identification (Sneath, 1972) giving no character an infinite weight. Other non-sporeforming Gram-positive anaerobes may have the same reactions in two or three of the selected tests, but we have not found this set of reactions in a strain of eubacteria or lactobacilli.

In the interpretation of the value of morphological characters for identification, no character was found to be sufficiently discriminative and mutually exclusive to justify its inclusion in a diagnostic table. However, these organisms have morphological features which, while not unique, when taken together might assist a practised eye to distinguish between genera (Moore \& Holdeman, 1970). Many of the morphological characters that might be considered typical for these organisms are subjective, and all are influenced by temperature, incubation time and the nutritional qualities of the basal medium (see, for example, Beerens et al. 1957; Sundman \& Björksten, 1958; Slack \& Gerencser, 1970b). Thus, they are variable because many of the factors that affect them are difficult to control.

Micro-colony morphology is a useful characteristic for recognizing an Actinomyces (Slack et al. 1969; Slack \& Gerencser, 1970 b) and also for differentiating the species. Although the presence of a filamentous micro-colony may be indicative of an Actinomyces, we have found such colonies to be extremely difficult to see and the dominant forms are diphtheroids, bifid, or even rod shaped. Since this property cannot be considered as a unit character acceptable for numerical taxonomy it was omitted from the analysis.

The tests for optimal growth under aerobic and anaerobic conditions were included as an initial basis for the differentiation of this group of organisms in accordance with the recommendations of the Subgroup on the Taxonomy of Micro-aerophilic Actinomycetes (1968). The anaerobic condition allowed good growth of all strains. Although strict anaerobiosis was an obligate requirement for Bifidobacterium species, it was not completely 
exclusive for Actinomyces, Arachnia or Propionibacterium species; some of these bacteria grow under aerobic conditions after continued laboratory culture, and the addition of $\mathrm{CO}_{2}$ stimulates the aerobic growth of Actinomyces species (Rosebury, I944; Buchanan \& Pine, 1965; Pine, 1970), being metabolized at a substrate level (Pine \& Howell, 1956). As judged by oxygen tolerance these organisms are to be characterized as moderate anaerobic organisms (Loesche, 1969).

Analysis of the metabolic end-products from glucose fermentation by the actinomycetes under strict anaerobic condition in the presence of added $\mathrm{CO}_{2}$ was found to be valuable for the differentiation of genera. The profiles of the gas-liquid chromatograms for volatile and non-volatile fatty acids were highly reproducible in repeated tests on the same strain and identical results were obtained when different instruments were used for the tests. The chromatograms are characteristic for Actinomyces, Arachnia, Bifidobacteria and Propionibacteria with respect to the production of acetic, propionic, isovaleric, lactic and succinic acids. Propionate formation was found to be characteristic for the Arachnia and the Propionibacterium strains; no propionic acid was produced by Actinomyces and Bifidobacterium strains. At this point our results are not in agreement with those of $\mathrm{Li} \&$ Georg (1968), who demonstrated trace amounts of propionic acid in the chromatographic analysis of volatile acids in the medium in which $A$. israelii and $A$. naeslundii had grown, but are consistent with those obtained from gas chromatographic analysis by Buchanan \& Pine (1962).

The information provided by gas chromatographic examination on a qualitative basis does not allow a proper differentiation between Actinomyces and bifidobacteria. However, a simple approximate estimation of the amounts of the acids produced, yielded information quite useful for their differentiation. Bifidobacteria produce acetic and lactic acid as their major metabolic products in the approximate ratio of $\mathrm{I} \cdot 5$ to $\mathrm{I} \cdot 0$, and trace amounts of succinic acid were occasionally detected, whereas the Actinomyces produce lactic acid and succinic acid as their major non-volatile acids, and acetic acid as the only major volatile acid. Certain points pertain to the effects of $\mathrm{CO}_{2}$ and the degree of anaerobiosis in the interpretation of these assays. Qualitative and quantitative changes in fermentation capacity of the Actinomyces are observed under anaerobic and aerobic conditions and in the presence or absence of $\mathrm{CO}_{2}$. The strains of Actinomyces incorporate added $\mathrm{CO}_{2}$, with a high production of succinic acid and smaller amounts of lactic acid, when glucose is fermented anaerobically (Rosebury, 1944; Pine \& Howell, 1956; Buchanan \& Pine, I965). Strains of Actinomyces, which can grow in aerated media in the presence of $\mathrm{CO}_{2}$, ferment glucose with the formation of only acetic acid (Buchanan \& Pine, I965; Pine, I970). However, under the anaerobic conditions we employed there is probably sufficient constancy in these characters to differentiate between Actinomyces and bifidobacteria.

The assays on acid end-products could also be useful for differentiating Actinomyces and bifidiobacteria from other related anaerobes, such as lactobacilli and eubacteria. Obligate anaerobic species of lactobacilli produce only lactic acid as a major product from glucose fermentation (Moore \& Holdeman, 1970, 1973). The definition of the genus Eubacterium has been emended to include organisms that do not produce the following as major products of fermentation: propionic acid; lactic acid alone; acetic and lactic acids together but with the amount of acetic acid exceeding that of lactic acid (Moore \& Holdeman, I973). Most species in this genus produce butyric and other acids; some species mainly produce acetic acid.

Some biochemical tests were used as additional tools in the differentiation of genera and species. Hydrolysis of aesculin was a constant feature of all Actinomyces species, except for A. odontolyticus. This property helped to differentiate Actinomyces from Arachnia pro- 
pionica and Propionibacterium acnes, but not from other propionibacteria and bifidobacteria. The anaerobic strains of Actinobacterium meyerii, which produce metabolic end-products of glucose fermentation similar to those of Actinomyces strains, could be separated from these organisms by their failure to hydrolyse aesculin. No strains of bifidobacteria reduced nitrate. This character merits being a key feature of bifidobacteria (Scardovi et al. I97I; Reuter, 1971) and separates them from the Actinomyces and Arachnia. In other reports (Slack \& Gerencser, 1970 c; Slack et al. 1969; Brock \& Georg, I969a; Georg, 1970; Moore \& Holdeman, 1970) nitrate reduction has not been a definite property of $A$. israelii, but all strains assigned as $A$. israelii in the present study reduced nitrate to nitrite in the oxygen-free indole-nitrite medium. Several factors may be responsible for these contradictory results, e.g. the capacity for assimilatory and respiratory nitrate reduction in aerated and prereduced media. The activity and production of nitrate reductase is suppressed in aerated media (Payne, 1973), and since Actinomyces israelii grows in limited aerated media, assays of nitrate reductase activity in such media might not have given detectable levels of nitrite. Production of indole was an exclusive character of all strains of $P$. acnes. The indole test proved to be useful for separating $P$. acnes from the Actinomyces and Arachnia as well as from other propionibacteria and bifidobacteria on which it is a latent 'contaminant'. An inverse correlation between indole production and nitrate reduction by $P$. acnes strains (Moore \& Holdeman, 1973) was not confirmed in the present work. The absence of catalase in Arachnia and Actinomyces, except for A. viscosus, serves to separate these genera from most members of the genus Propionibacterium.

Acid formation from carbohydrates is not a truly independent characteristic for anaerobes, as variations occur in the carbohydrate fermentation under different degrees of anaerobiosis and a fall in $\mathrm{pH}$ value accompanies high $\mathrm{CO}_{2}$ tension (Watt, I973; Anaerobe Laboratory Manual, 1973). Nevertheless, from the results we concluded that some reactions were of value in identification, provided that the carbohydrate concentration in the fermentation medium was reduced to $\mathrm{I} \%(\mathrm{w} / \mathrm{v})$ and that phosphate $(\mathrm{I} \cdot 5 \%, \mathrm{w} / \mathrm{v})$ was used as a buffer. The characteristics listed in the diagnostic table indicate reactions of cultures in which there was excellent growth after 5 days or more of incubation at $37^{\circ} \mathrm{C}$. Acid production from mannitol was a property shared by Ar. propionica and some $A$. israelii, but not by other Actinomyces species. The reaction with xylose differentiated between $A r$. propionica and $A$. israelii. Actinomyces israelii serotype 2 failed to ferment arabinose, and sorbitol-fermenting strains of $P$. acnes belonged to serotype I of this species.

In practice, bacterial specimens sampled and transported in pre-reduced media are cultivated in PRAS PYG roll streak-tubes or on freshly prepared pre-reduced PYG medium in plates, inoculated in a GasPac atmosphere. Colonies of Gram-positive non-sporeforming pleomorphic rods from primary anaerobic tubes or plates are subcultured to determine purity and tested for sensitivity to $\mathrm{O}_{2}$ by culture on aerated PYG medium. Pure anaerobes are cultured on PRAS broth in $\mathrm{CO}_{2}$-gassed tubes in duplicate. Five-day-old cultures are subjected to gas chromatographic analyses for end-products from glucose fermentation, and to a series of biochemical tests. For this purpose one PRAS PYG broth culture is washed under continuous anaerobiosis in pre-reduced salt solution and a bacterial suspension with an extinction of approximately 0.2 at $540 \mathrm{~nm}$ is prepared. This suspension is aspirated in a gassed-out syringe and portions are inoculated into tubes containing the differential media: aesculin, indole-nitrite and fermentation bases with mannitol, xylose, arabinose and sorbitol. Alternatively, the application of immunofluorescence in identification of the species of Actinomyces and Arachnia is as efficient (Holmberg \& Forsum, 1973) as determination of biochemical characteristics, as well as being simpler and quicker. 
The background work for this investigation was supported by grants from Västmanlandsläns landsting, Västerås, Sweden. The assistance of G. Karlsten with computing is gratefully acknowledged.

\section{REFERENCES}

Anaerobe Laboratory Manual (1973). Edited by L. V. Holdeman and W. E. C. Moore. Blackburg, Virginia: Virginia Polytechnic Institute and State University.

AtTeberY, H. R. \& Finegold, S. M. (I969). Combined screw-cap and rubber-stopper closure for Hungate tubes (pre-reduced anaerobically sterilized roll-tubes and liquid media). Applied Microbiology 18, $558-56 \mathrm{I}$.

BATTY, J. (1958). Actinomyces odontolyticus, a new species of actinomycete regularly isolated from deep carious dentine. Journal of Pathology and Bacteriology 75, 455-459.

Beerens, H., Gérard, A. \& Guillame, J. (1957). Étude de 30 souches de Bifidobacterium bifidum (Lactobacillus bifidum). Charactérization d'une varieté buccale. Comparison avec les souches d'origine fécale. Annales de l'Institut Pasteur 9, 77-85.

Bergey's Manual of Determinative Bacteriology (1974). 8th edn. Edited by R. E. Buchanan and N. E. Gibbons. Baltimore: The Williams and Wilkins Co.

Blank, C. H. \& GeORG, L. K. (1968). The use of fluorescent antibody methods for the detection and identification of Actinomyces species in clinical material. Journal of Laboratory and Clinical Medicine 7r, 283-293.

Boone, C. J. \& PINE, L. (I968). Rapid method for characterization of actinomycetes by cell wall composition. Applied Microbiology 16, 279-284.

Bouisset, L., Breuillaud, J., Michel, G. \& Larrouy, G. (I968). Bases nucléiques des bactéries application au genre Actinobacterium. Annales de l'Institut Pasteur 115, 1063-108I.

Bowden, G. \& Hardie, J. (1973). Commensal and pathogenic Actinomyces species in man. In Actinomycetales: Characteristics and Practical Importance, pp. 177-293. Edited by G. Sykes and F. A. Skinner. London and New York: Academic Press.

Brock, D. W. \& GeORG, L. K. (1969a). Characterization or Actinomyces israelii, serotypes I and 2. Journal of Bacteriology 97, 589-593.

Brock, D. W. \& GEORG, L. K. (1969b). Determination and analysis of Actinomyces israelii serotypes by fluorescent antibody procedures. Journal of Bacteriology 97, 58I-588.

Brock, D. W., Georg, L. K., Brown, J. M. \& Hicklin, M. D. (1973). Actinomycosis caused by Arachnia propionica. American Journal of Clinical Pathology 59, 66-76.

Brzin, B. (1965). Comparative studies on anaerobic corynebacteria and actinomycetes. Acta pathologica et microbiologica scandinavica 63, 415-42I.

Buchanan, B. B. \& PINE, L. (I962). Characterization of a propionic acid producing actinomycete, Actinomyces propionicus, sp. nov. Journal of General Microbiology 28, 305-323.

Buchanan, B. B. \& Pine, L. (1965). Relationship of carbon dioxide to aspartic acid and glutamic acid in Actinomyces naeslundii. Journal of Bacteriology 89, 729-733.

CowAn, S. T. \& SteEL, K. J. (1970). Manual for the Identification of Medical Bacteria. Cambridge: Cambridge University Press.

Cross, T. \& Goodfellow, M. (1973). Taxonomy and classification of the actinomycetes. In Actinomycetales: Characteristics and Practical Importance, pp. I I-III. Edited by G. Sykes and F. A. Skinner. London and New York: Academic Press.

Cummins, C. S. (1970). Actinomyces israelii, type 2. In The Actinomycetales, pp. 29-34. Edited by H. Prauser. Jena: G. Fischer.

DeHNERT, J. (1957). Untersuchungen über die Gram positive Stuhlflora des Brustmilch-Kindes. Zentralblatt fïr Bakteriologie, Parasitenkunde, Infektionskrankheiten und Hygiene (Abteilung I) r69, 66-79.

De WeEse, M. S., GerencSer, M. A. \& SlACK, J. M. (1968). Quantitative analysis of Actinomyces cell walls. Applied Microbiology 16, 1713-1718.

GEORG, L. K. (1970). Diagnostic procedures for the isolation and identification of the etiologic agents of actinomycosis. In Proceedings International Symposium on Mycoses, pp. 71-80. Washington, D.C.: World Health Organization.

Georg, L. K., Roberstad, G. W. \& Brinkman, S. A. (1964). Identification of species of Actinomyces. Journal of Bacteriology 88, 477-490.

Georg, L. K., Roberstad, G. W., Brinkman, S. A. \& Hicklin, M. D. (1965). A new pathogenic anaerobic Actinomyces species. Journal of Infectious Diseases II5, 88-99. 
GERENCSER, M. A. \& SLACK, J. M. (1969). Isolation and characterization of Actinomyces propionicus. Journal of Bacteriology 94, I09-I I 5.

Goodall, D. W. (1967). The distribution of the matching coefficient. Biometrics 23, 647-656.

GyllenberG, H. G. (I965). A model for computer identification of micro-organisms. Journal of General Microbiology 39, 40I-405.

Holm, P. (1930). Comparative studies on some pathogenic anaerobic actinomyces. Acta pathologica et microbiologica scandinavica 3, 15 I-156.

Holm, P. (1948). Some investigation into the penicillin sensitivity of human-pathogenic actinomycetes. Acta pathologica et microbiologica scandinavica 25, 376-404.

Holmberg, K. (1975). Isolation and identification of Gram positive rods in human dental plaques. Archives of Oral Biology (in the Press).

Holmberg, K. \& Forsum, U. (I973). Identification of Actinomyces, Arachnia, Bacterionema, Rothia and Propionibacteria species by defined immunofluorescence. Applied Microbiology 25, 834-843.

Holmberg, K. \& Hallander, H. O. (1973). Numerical taxonomy and laboratory identification of Bacterionema matruchotii, Rothia dentocariosa, Actinomyces naeslundii, Actinomyces viscosus and some related bacteria. Journal of General Microbiology 76, 43-63.

Holmberg, K., Nord, C.-E. \& Wadström, T. (I975a). Serological study of Actinomyces israelii by crossed immunoelectrophoresis. Standard antigen-antibody system for A. israelii. Infection and Immunity 12, 387-397.

Holmberg, K., Nord, C.-E. \& Wadström, T. (1975 b). Serological study of Actinomyces israelii by crossed immunoelectrophoresis. Taxonomic and diagnostic applications. Infection and Immunity 12, 398-403.

Johnson, J. L. \& Cummins, C. D. (1972). Cell wall composition and deoxyribonucleic acid similarities among the anaerobic coryneforms, classical propionibacteria, and strains of Arachnia propionica. Journal of Bacteriology 109, 1047-1066.

Lambert, F. W., JUn., Brown, J. M. \& GeorG, L. K. (1967). Identification of Actinomyces israelii and Actinomyces naeslundii by fluorescent-antibody and agar-gel diffusion techniques. Journal of Bacteriology 94, I 287-1 297.

Li, Yu-YIng, F. \& Georg, L. K. (1968). Differentiation of Actinomyces israelii and Actinomyces naeslundii by gas chromatography. Canadian Journal of Microbiology 14, 749-753.

Liston, J., Weibe, W. \& ColWell, R. R. (1963). Quantitative approach to the study of bacterial species. Journal of Bacteriology 85, $106 \mathrm{I}-\mathrm{I} 070$.

LoesCHe, W. J. (1969). Oxygen sensitivity of various anaerobic bacteria. Applied Microbiology 18, 723-727.

Macy, J. M., Snellen, J. E. \& Hungate, R. E. (1972). Use of syringe methods for anaerobiosis. American Journal of Clinical Nutrition 25, $1318-1323$.

Melville, T. H. (1965). A study of the overall similarity of certain actinomycetes mainly of oral origin. Journal of General Microbiology 40, 309-315.

Methods for Numerical Taxonomy (I970). Edited by W. R. Lockhart and J. Liston. Bethesda, Maryland: American Society for Microbiology.

MitsoukA, T. (1969). Vergleichende Untersuchungen über die Bifidobakterien aus dem Verdauungstrakt von Menschen und Tieren. Zentralblatt für Bakteriologie, Parasitenkunde, Infektionskrankheiten und Hygiene (Abteilung I) 210, 52-64.

Moore, W. E. C. (1966). Techniques for routine culture of fastidious anaerobes. International Journal of Systematic Bacteriology 16, I73-190.

Moore, W. E. C. \& Holdeman, L. V. (1970). Gram-positive nonsporeforming anaerobic bacilli. In Manual of Clinical Microbiology, pp. 290-295. Edited by J. E. Blair, E. H. Lennertte and J. P. Truant. Bethesda, Maryland: American Society for Microbiology.

Moore, W. E. C. \& Holdeman, L. V. (1973). New names and combinations in the genera Bacteroides Castellani and Chalmers, Fusobacterium Knorr, Eubacterium Prévot, Propionibacterium Delwich, and Lactobacillus Orla-Jensen. International Journal of Systematic Bacteriology 23, 69-74.

Moore, W. E. C., Holdeman, L. V. \& Cummins, C. S. (1968). Objection: Corynebacterium acnes is not the sole legitimate anaerobe species of the Corynebacterium. International Journal of Systematic Bacteriology 18, 273-274.

PAyne, W. J. (I973). Reduction of nitrogenous oxides by micro-organisms. Bacteriological Reviews 37, 409-452.

PINE, L. (1970). Classification and phylogenetic relationship of micro-aerophilic actinomycetes. International Journal of Systematic Bacteriology 20, 445-474.

PINe, L. \& GeORG, L. K. (1969). Reclassification of Actinomyces propionicus. International Journal of Systematic Bacteriology 19, 267-272. 
PINE, L. \& HARdin, H. (1959). Actinomyces israelii: a cause of lacrimal canaliculitis in man. Journal of Bacteriology 78, 164-170.

PINe, L. \& Howell, H., JUN. (1956). Comparison of physiological and biochemical characters of Actinomyces species with those of Lactobacillus bifidus. Journal of General Microbiology 15, 428-445.

Poupard, J. A., HuSAIN, J. \& Norris, R. F. (1973). Biology of the bifidobacteria. Bacteriological Reviews $37,136-165$.

Prévot, A. R. (1938). Études de systematique bactérienne. Annales de l'Institut Pasteur 60, 285-307.

Prévot, A. R. (196I). Traité de systematique bacterienne, vol. 2. Paris: Dunrod.

Prévot, A. R. (1966). Manual for the Classification and Determination of the Anaerobic Bacteria. Philadelphia: Lea and Febiger.

PrÉvot, A. R. (1972). Les bactéries anaérobies. Lille: Crouan et Roques.

Prévot, A. R., Turpin, A. \& KaISeR, P. (1967). Les bactéries anaérobies. Paris: Dunrod.

Puhvel, S. M. (1968). Characterization of Corynebacterium acnes. Journal of General Microbiology 50, 313-320.

Pulverer, G. \& Ko, H. L. (1973). Fermentative and serological studies on Propionibacterium acnes. Applied Microbiology 25, 222-229.

Puntoni, V. (1937). Sulle relazioni fra il b. bifidio e gli attinomiceti anaerobi tipo Wolff-Israel. Annali d'igiene sperimentale 47, 157-168.

REID, J. D. \& JoYA, M. A. (1969). A study of the morphologic and biochemical characteristics of certain anaerobic corynebacteria. International Journal of Systematic Bacteriology 19, 272-280.

REUTER, G. (1963). Vergleichende Untersuchungen über die Bifidus Flora in Säuglings- und Erwachsenenstuhl. Zentralblatt für Bakteriologie, Parasitenkunde, Infektionskrankheiten und Hygiene (Abteilung I) I9I, 486-507.

REUTER, G. ( I971). Designation of type strains for Bifidobacterium species. International Journal of Systematic Bacteriology 21, 273-275.

ROSEBURY, T. (I944). The parasitic actinomycetes and other filamentous micro-organisms of the mouth: a review of their characteristics and relationships of the bacteriology of actinomycosis and of salivary calculus in man. Bacteriological Reviews 8, 89-106.

Scardovi, V. \& Crociani, F. (1974). Bifidobacterium catenulatum, Bifidobacterium dentium and Bifidobacterium angulatum: three new species and their deoxyribunocleic acid homology relationships. International Journal of Systematic Bacteriology 24, 6-20.

Scardovi, V., Trovatelli, L. D., Zani, G., Crociani, F. \& Mattenzzi, D. (197I). Deoxyribonucleic acid homology relationships among species of the genus Bifidobacterium. International Journal of Systematic Bacteriology 21, 276-294.

Slack, J. M. \& Gerencser, M. A. (1970a). Two new serological groups of Actinomyces. Journal of Bacteriology 103, 266-267.

SlACK, J. M. \& GerenCSER, M. A. (1970 b). Range of cellular and colonial morphologies of Actinomyces israelii. International Journal of Systematic Bacteriology 20, 259-268.

Slack, J. M. \& Gerencser, M. A. (I970 c). The genus Actinomyces. In The Actinomycetales, pp. 19-27. Edited by H. Prauser. Jena: G. Fischer.

Slack, J. M., Landfried, S. \& Gerencser, M. A. (1969). Morphological, biochemical and serological studies of 64 strains of Actinomyces israelii. Journal of Bacteriology 97, 873-884.

SNEATH, P. H. A. (I957). The application of computers to taxonomy. Journal of General Microbiology $\mathbf{1 7}$, 20I-226.

SNEATH, P. H. A. (1968). Vigour and pattern in taxonomy. Journal of General Microbiology 54, I-I I.

SNeAth, P. H. A. (1970). Application of numerical taxonomy to Actinomycetales: problems and prospects. In The Actinomycetales, pp. 371-377. Edited by H. Prauser. Jena: V. E. B. Fischer.

SNeAth, P. H. A. (1972). Computer taxonomy. In Methods in Microbiology, vol. 7A, pp. 29-98. Edited by J. R. Norris and D. W. Ribbons. London: Academic Press.

SNeAth, P. H. A. \& Johnson, R. (1972). The influence on numerical taxonomic similarities of errors in microbiological tests. Journal of General Microbiology 72, 377-392.

Sneath, P. H. A. \& Sokal, R. R. (1973). Numerical Taxonomy. San Francisco: W. H. Freeman.

Snyder, M. L., Slawson, M. S., Bullock, W. \& Parker, R. B. (1967). Studies on oral filamentous bacteria. II. Serological relationships between the genera Actinomyces, Nocardia, Bacterionema and Leptotrichia. Journal of Infectious Diseases 47, 341-345.

Sokal, R. R. \& Michener, C. D. (I958). A statistical method for evaluating systematic relationships. Kansas University Science Bulletin 38, 1409-1438.

Sokal, R. R. \& RoHLF, F. J. (I962). The comparison of dendrograms by objective methods. Taxon II, 33-40. 
SoKal, R. R. \& SNeAth, P. H. A. (1963). Principles of Numerical Taxonomy. San Francisco: W. H. Freeman. SUBGROUP ON THE TAXONOMY OF MiCRO-AEROPHILIC ACTINOMYCETES (1968). International Journal of Systematic Bacteriology 18, 253-262.

Sundman, V. \& BJöRKSTEN, K. (1958). The globular involution of the bifid bacteria. Journal of General Microbiology 19, 49I-496.

Voss, J. G. (1970). Differentiation of two groups of Corynebacterium acnes. Journal of Bacteriology 1or, 392-397.

WATT, B. (1973). The influence of carbon dioxide on the growth of obligate facultative anaerobes on solid media. Journal of Medical Microbiology 6, 307-314.

WolfF, M. \& ISRAEL, J. (189I). Ueber Reincultur des Actinomyces und seine Uebertragbarkeit auf Thiere. Virchows Archiv für pathologische Anatomie und Physiologie und für klinische Medizin 126, I I-59.

Zeirdt, C. H., Webster, C. \& RUdE, W. S. (1968). Study of the anaerobic corynebacteria. International Journal of Systematic Bacteriology 18, 33-47. 